Cite this: Phys. Chem. Chem. Phys., 2011, 13, 8379-8391

\title{
Potential energy surfaces for gas-surface reactions $\dagger$
}

\author{
Terry J. Frankcombe* and Michael A. Collins* \\ Received 17th September 2010, Accepted 12th January 2011 \\ DOI: $10.1039 / \mathrm{c0cp01843k}$
}

A method for constructing the potential energy surface for reactions of a molecule with the surface of cleaved non-conducting crystals is reported. The method uses systematic fragmentation to express the total potential in terms of potential energy surfaces which describe reactions of relatively small molecules in the gas phase. The approach is illustrated by an application to the reaction of hydrogen atoms with a hydrogen-terminated silicon(111) surface.

\section{Introduction}

The theoretical and computational study of chemical reaction dynamics requires accurate Born-Oppenheimer potential energy surfaces (PESs). The most reliably accurate PESs are constructed from $a b$ initio calculations of the total electronic energy of the reacting system. There has been substantial progress in constructing PESs from $a b$ initio data for the reactions of relatively small molecules in the gas phase. ${ }^{1-11}$ For reactions between molecules and solid surfaces, progress has been confined to reactions at metal surfaces. ${ }^{12-17}$ For metals, the electronic energy calculations are restricted to density functional methods on "slabs" of metallic crystal under periodic boundary conditions.

However, it has recently been demonstrated ${ }^{18}$ that the $a b$ initio methods normally applied to gas phase molecules can be applied to non-metallic, non-conducting, crystals. This approach involves the systematic fragmentation of crystals into relatively small molecules for which $a b$ initio methods are applicable. The total electronic energy of the crystal (per unit cell) is given by sums and differences of these molecular energies. This approach differs from traditional methods which evaluate the electronic wavefunction or electron density of crystals under periodic boundary conditions. ${ }^{19}$ Electron correlation can also be accounted for using local second order Møller-Plesset perturbation theory (MP2) under periodic boundary conditions. ${ }^{20-23}$ Systematic fragmentation adopts a localised view of the electronic structure. In this respect, it is also similar in spirit to the methods of Stoll, Fulde and coworkers which evaluate the correlation energy of crystals using localised bond orbitals. ${ }^{24-29}$ Other localised approaches

Research School of Chemistry, Australian National University,

ACT 0200,Australia.E-mail: tjf@rsc.anu.edu.au; collins@rsc.anu.edu.au

$\dagger$ Electronic supplementary information (ESI) available: Complete descriptions of the fragmentation of silicon(111) and (100) surfaces; and the data sets and software for potential energy surfaces for reactions (3.2) and (3.3). See DOI: 10.1039/c0cp01843k which may be applied to crystal surfaces rely on the use of finite clusters to model the surface, ${ }^{30}$ clusters imbedded in a medium which represents the bulk of the crystal, ${ }^{31,32}$ or related QM/MM methods. ${ }^{33}$ In this paper, we show how systematic fragmentation can be applied to cleaved crystals and to reactions between the crystal surfaces and molecules impinging on the surface.

Systematic molecular fragmentation (SMF) of gas phase molecules has been shown $^{34,35}$ to provide a method for calculating the $a b$ initio energy of a large gas-phase molecule to within chemical accuracy (a few $\mathrm{kJ} \mathrm{mol}^{-1}$ ). This approach provides a hierarchy of estimates for the molecular electronic energy. We can consider the lowest member of this hierarchy (so-called Level 1) as providing the complete PES of a large molecule in terms of the PESs of quite small molecular fragments. Higher levels of fragmentation produce larger molecular fragments. Improvements to the accuracy of the total PES can be cast in terms of potential energy correction surfaces (PECSs), which describe the difference in the energy estimates from Level $(n-1)$ to Level n. PECSs may be much easier, computationally, to construct than are PESs for moderate to large molecules, even though higher level PECSs are functions of higher dimensions. This combination of small molecule PESs with larger dimensional PECSs was used to construct an approximate $a b$ initio PES for the reactions of hydrogen with $n$-pentane. ${ }^{36}$ Here, we show that a similar approach is possible for the reaction of molecules at cleaved crystal surfaces.

The method is illustrated by constructing the Level 1 PES for the reaction of hydrogen atoms with a hydrogen-terminated silicon(111) surface. Reactions of molecules with and on silicon surfaces have been the subject of intense experimental study over the last 15 years. $^{37-43}$ This work is motivated by potential applications in nano-lithography and semiconductor devices. In the context of molecular reaction dynamics, this system provides a very convenient benchmark or test case for the development of both PESs and dynamical methods. 
The paper is set out as follows. In section 2, the general methodology for fragmenting cleaved crystals is presented. This relies heavily on the detailed algorithms (and computer programs) developed previously for large gas-phase molecules and for infinite crystal lattices. Hence, the algorithmic details are not reprised herein. Expression of the total PES in terms of the PESs and PECSs for small molecular fragments is described. Details of the fragmentation results for silicon surfaces are included in supplementary material. Section 3 presents evidence for the accuracy of this fragmentation approach for the reaction of a hydrogen atom with a hydrogen-terminated silicon(111) surface. Section 4 contains the details of the small molecule $\left(\mathrm{H}+\mathrm{SiH}_{4}\right.$ and $\left.\mathrm{H}+\mathrm{Si}_{2} \mathrm{H}_{6}\right)$ PESs required for a Level 1 PES of the whole system. These PESs are constructed using modified Shepard interpolation. ${ }^{8}$ Section 5 presents some features of the Level 1 PES for the reaction of a hydrogen atom with a hydrogen-terminated $\mathrm{Si}(111)$ surface. The last section contains some concluding remarks.

\section{Systematic fragmentation of cleaved crystals}

\subsection{Background}

In recent years, a number of groups have developed related approaches to estimating molecule and cluster energies by fragmenting the system into smaller molecules. ${ }^{34,44-53}$ The method of systematic molecular fragmentation (SMF) has previously been applied to the calculation of ab initio energies for molecules ${ }^{34,35,48}$ and non-conducting crystals. ${ }^{18}$ In this approach, the molecular or crystal structure is expressed as the sum (and difference) of small molecular fragments. These fragments are produced by breaking bonds between functional groups (in the ordinary chemical sense) in the original structure and restoring the valence bonding by "capping" each radical so produced by a hydrogen atom. The total electronic energy of the system is expressed as the corresponding sum of the energies of the fragments. The method is hierarchical, meaning that there are a series of approximations, denoted as Level 1, Level 2, and so on, in which the fragments increase in size. In simple terms, at Level n, two bonds can be broken simultaneously only if they are separated by $\mathrm{n}$ functional groups. The corresponding approximation to the molecular or crystal energy has been shown to improve in accuracy as the Level increases, reaching chemical accuracy of about $2 \mathrm{~kJ} \mathrm{~mol}^{-1}$ at Level 3 (if long range interactions are also treated perturbatively). ${ }^{35} \mathrm{~A}$ complete description of the methodology ${ }^{18,34}$ will not be repeated herein, but a simple model example is useful.

Consider a simple one-dimensional "crystal" or periodic array, based on a unit cell containing three functional groups, denoted ABC:

$$
C_{1 D} \equiv \cdots \mathrm{A}_{n-1} \mathrm{~B}_{n-1} \mathrm{C}_{n-1} \mathrm{~A}_{n} \mathrm{~B}_{n} \mathrm{C}_{n} \mathrm{~A}_{n+1} \mathrm{~B}_{n+1} \mathrm{C}_{n+1} \cdots
$$

At Level 1, the array is fragmented in an infinite sequence of one and two functional groups:

$$
C_{1 D}^{(\text {Level I })} \rightarrow \sum_{n=-\infty}^{\infty}\left[\mathrm{B}_{n-1} \mathrm{C}_{n-1}+\mathrm{C}_{n-1} \mathrm{~A}_{n}+\mathrm{A}_{n} \mathrm{~B}_{n}-\mathrm{C}_{n-1}-\mathrm{A}_{n}-\mathrm{B}_{n}\right]
$$

The fragments, e.g. $\mathrm{C}_{n-1} \mathrm{~A}_{n}$ including the capping hydrogen atoms, are simple molecules. At Level 2:

$$
\begin{aligned}
C_{1 D}^{(\text {Level 2) }} \rightarrow & \sum_{n=-\infty}^{\infty}\left[\mathrm{B}_{n-1} \mathrm{C}_{n-1} \mathrm{~A}_{n}+\mathrm{C}_{n-1} \mathrm{~A}_{n} \mathrm{~B}_{n}+\mathrm{A}_{n} \mathrm{~B}_{n} \mathrm{C}_{n}\right. \\
& \left.-\mathrm{B}_{n-1} \mathrm{C}_{n-1}-\mathrm{C}_{n-1} \mathrm{~A}_{n}-\mathrm{A}_{n} \mathrm{~B}_{n}\right]
\end{aligned}
$$

The corresponding expression for the energy is

$$
\begin{aligned}
E_{1 D}^{(\text {Level 2) }}= & \sum_{n=-\infty}^{\infty}\left[E\left(\mathrm{~B}_{n-1} \mathrm{C}_{n-1} \mathrm{~A}_{n}\right)+E\left(\mathrm{C}_{n-1} \mathrm{~A}_{n} \mathrm{~B}_{n}\right)+E\left(\mathrm{~A}_{n} \mathrm{~B}_{n} \mathrm{C}_{n}\right.\right. \\
& \left.\left.-E\left(\mathrm{~B}_{n-1} \mathrm{C}_{n-1}\right)-E\left(\mathrm{C}_{n-1} \mathrm{~A}_{n}\right)-E\left(\mathrm{~A}_{n} \mathrm{~B}_{n}\right)\right)\right]
\end{aligned}
$$

Here $E(\cdots)$ represents the ground state ab initio electronic energy of a molecule composed of the functional groups with additional hydrogen atom caps. The sum of energies enclosed in square brackets on the rhs of eqn (2.4) corresponds to the energy of the infinite lattice per unit cell. This hierarchy of fragmentations is the result of a simple hierarchy of rules governing the proximity of bonds that may be simultaneously broken. These rules have been incorporated in a computer algorithm, so that any molecule ${ }^{54}$ or crystal ${ }^{18}$ structure can be systematically fragmented. For crystals, we note that the terms in square brackets in eqn (2.2)-(2.4) are periodically reproduced in an infinite sum.

For a periodic crystal lattice in three dimensions, the positions of the atoms are related to the positions of the atoms in a given unit cell:

$\mathbf{x}\left(m, l_{1}, l_{2}, l_{3}\right)=\mathbf{x}(m, 0,0,0)+l_{1} \mathbf{a}(1)+l_{2} \mathbf{a}(2)+l_{3} \mathbf{a}(3),(2.5)$

where $m=1, \ldots, N_{\mathrm{u}}\left(N_{\mathrm{u}}\right.$ is the number of atoms in the unit cell), $l_{1}, l_{2}$, and $l_{3}$ are integers, and $\mathbf{a}(1), \mathbf{a}(2)$ and $\mathbf{a}(3)$ denote the lattice vectors. We identify each atom in the crystal by its unique labels $\left(m, l_{1}, l_{2}, l_{3}\right)$. Systematic fragmentation of the crystal produces molecular fragments which contains atoms in the "central unit cell" (and possibly additional atoms in adjacent unit cells), and an infinite number of fragments which are equivalent to these, but which contain atoms displaced along the lattice vectors as in eqn (2.5). A fragment that is associated with the central unit cell is denoted by $F_{n}(0,0,0)$. A fragment that is related by a simple lattice translation is denoted by $F_{n}\left(k_{1}, k_{2}, k_{3}\right)$, and by definition if atom $\left(m, l_{1}, l_{2}, l_{3}\right)$ is contained in $F_{n}(0,0,0)$, then $\left(m, k_{1}+l_{1}, k_{2}+l_{2}, k_{3}+l_{3}\right)$ is contained in $F_{n}\left(k_{1}, k_{2}, k_{3}\right)$. So, in the one-dimensional example of eqn (2.2) if $F_{2}(0)=\mathrm{C}_{-1} \mathrm{~A}_{0}$, then $F_{2}(k)=\mathrm{C}_{k-1} \mathrm{~A}_{k}$. In general, the fragmented crystal structure is denoted as

$$
C \rightarrow \sum_{k_{1}=-\infty}^{\infty} \sum_{k_{2}=-\infty}^{\infty} \sum_{k_{3}=-\infty}^{\infty} \sum_{n=1}^{N_{\text {frag }}} f_{n} F_{n}\left(k_{1}, k_{2}, k_{3}\right),
$$

where the coefficients $\left\{f_{n}\right\}$ are simple integers, like $\pm 1 . N_{\text {frag }}$ denotes the number of unique fragments. The complete computer algorithm for obtaining eqn (2.6) from a given crystal structure was reported previously. ${ }^{18}$

\subsection{Cleaved crystals}

Now suppose, that instead of an infinite crystal structure, we consider a structure that is only semi-infinite. That is a crystal 
that is truncated at a surface, $C_{\text {surf; }}$, herein a surface that corresponds to a "crystal plane". To continue the one-dimensional model example, suppose that

$$
C_{\text {surf }} \equiv \mathrm{B}_{1} \mathrm{C}_{1} \mathrm{~A}_{2} \mathrm{~B}_{2} \mathrm{C}_{2} \cdots \mathrm{A}_{n} \mathrm{~B}_{n} \mathrm{C}_{n} \cdots
$$

Then, the Level 2 fragmentation algorithm gives

$C_{\text {surf }}^{\text {(Level 2) }} \rightarrow \mathrm{B}_{1} \mathrm{C}_{1} \mathrm{~A}_{2}+\mathrm{C}_{1} \mathrm{~A}_{2} \mathrm{~B}_{2}-\mathrm{C}_{1} \mathrm{~A}_{2}+\mathrm{A}_{2} \mathrm{~B}_{2} \mathrm{C}_{2}-\mathrm{A}_{2} \mathrm{~B}_{2}+\cdots$

That is,

$$
\begin{aligned}
C_{\text {surf }}^{(\text {Level 2) }} \rightarrow & \mathrm{B}_{1} \mathrm{C}_{1} \mathrm{~A}_{2}-\mathrm{C}_{1} \mathrm{~A}_{2} \\
& +\sum_{n=1}^{\infty}\left[\mathrm{C}_{n} \mathrm{~A}_{n+1} \mathrm{~B}_{n+1}+\mathrm{A}_{n+1} \mathrm{~B}_{n+1} \mathrm{C}_{n+1}+\mathrm{B}_{n+1} \mathrm{C}_{n+1} \mathrm{~A}_{n+2}\right. \\
& \left.-\mathrm{A}_{n+1} \mathrm{~B}_{n+1}-\mathrm{B}_{n+1} \mathrm{C}_{n+1}-\mathrm{C}_{n+1} \mathrm{~A}_{n+2}\right]
\end{aligned}
$$

Clearly, the regular structure of "half" the lattice appears in eqn (2.9), plus two terms which account for the irregular structure at the "surface". The general result for fragmentation of a cleaved three dimensional crystal is similar, but requires a modification that we can demonstrate with a two dimensional example. Regular crystal surfaces are obtained by cleaving a crystal along a plane of symmetry, called a crystal plane. Such planes are labelled by their Miller indices (hkl). ${ }^{55}$ Fig. 1 depicts the equivalent situation for a fictitious two dimensional periodic lattice which has been cleaved along a line with Miller indices (32). The lattice vectors, $\mathbf{a}$ and $\mathbf{b}$, chosen for the bulk crystal are shown; the unit cell is rectangular in shape and contains just three atoms. When the lattice is cleaved, the symmetry is altered. A primitive unit cell which can periodically reproduce the cleaved crystal is indicated by the lattice vectors $\mathbf{a}^{\prime}$ and $\mathbf{b}^{\prime}$; the unit cell is a parallelogram containing nine atoms. In the general three-dimensional case, once the Miller indices of the cleavage plane are defined, and one surface lattice position is specified, two new lattice vectors $\left(\mathbf{b}^{\prime}\right.$ and $\left.\mathbf{c}^{\prime}\right)$ can be defined as (non-collinear) vectors connecting equivalent atoms in the plane, while the third lattice vector, $\mathbf{a}^{\prime}$, can be chosen to connect equivalent atoms in adjoining planes (simply one of the lattice vectors of the bulk crystal). The atoms which comprise the unit cell are then easily evaluated.

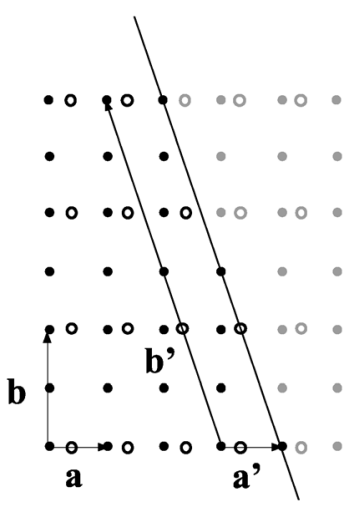

Fig. 1 A model two dimensional lattice is sketched; showing lattice vectors a and $\mathbf{b}$, a cleavage line with Miller indices (32), and the corresponding lattice vectors $\mathbf{a}^{\prime}$ and $\mathbf{b}^{\prime}$ (see text). The cleaved-off or discarded atoms are indicated in grey-tone.
In general, we must also specify the sense $( \pm)$ of the $\mathbf{a}^{\prime}$ axis that determines which atoms are "cleaved off". In Fig. 1, the atoms which have been cleaved off are indicated in grey. Herein, atoms with negative coordinates on the $\mathbf{a}^{\prime}$ axis are retained in the cleaved crystal (the grey atoms in Fig. 1 have positive coordinates on the $\mathbf{a}^{\prime}$ axis).

Now, the bulk crystal structure can be fragmented using the established algorithm to give eqn (2.6) in terms of the new unit cell, defined by $\mathbf{a}^{\prime}, \mathbf{b}^{\prime}, \mathbf{c}^{\prime}$. Then, it is a relatively simple matter to remove all references in eqn (2.6) to atoms that have been cleaved off the crystal. This means that "half" the unit cells in the bulk crystal are removed and also that some fragments which occur in the remaining bulk of the crystal are not present near the crystal surface. For example, if a fragment ABCD occurs in the bulk, but a B atom is cleaved off, then only near the surface ABCD must be replaced by the sum of two smaller fragments, $\mathrm{A}+\mathrm{CD}$.

This means that eqn (2.6) is replaced by

$$
\begin{aligned}
C_{\text {surf }} \rightarrow & \sum_{k_{1}=-\infty}^{-1} \sum_{k_{2}=-\infty}^{\infty} \sum_{k_{3}=-\infty}^{\infty} \sum_{n=1}^{N_{\text {frag }}} f_{n} F_{n}\left(k_{1}, k_{2}, k_{3}\right) \\
& +\sum_{k_{2}=-\infty}^{\infty} \sum_{k_{3}=-\infty}^{\infty} \sum_{n=1}^{N_{\text {frag }}^{\text {surf }}} g_{n} G_{n}\left(k_{2}, k_{3}\right),
\end{aligned}
$$

where decreasing $k_{1}$ corresponds to translation of the unit cell away from the cleaved surface, while changes in $k_{2}$ and $k_{3}$ correspond to translation of the unit cell parallel to the surface. $N_{\text {frag }}^{\text {surf }}$ denotes the number of unique fragments in the surface layer.

The "surface fragments", $G_{n}$, and the corresponding coefficients, $g_{n}$, are evaluated as follows. We consider each of the bulk fragments, $F_{n}\left(k_{1}, k_{2}, k_{3}\right)$, in turn. Each fragment is translated along the $\mathbf{a}^{\prime}$ direction [effectively redefining $F_{n}\left(0, k_{2}, k_{3}\right)$ ] so that no atom in $F_{n}\left(-1, k_{2}, k_{3}\right)$ has an $\mathbf{a}^{\prime}$ coordinate greater than zero. Then a new set of fragments is defined by combining sets $\left\{F_{n}\left(0, k_{2}, k_{3}\right)\right\} \cup\left\{F_{n}\left(1, k_{2}, k_{3}\right)\right\} \cup \cdots$. This union is terminated at $k_{1}$ greater than some number for which all atoms in the set have positive a' coordinates (so that the whole set, $\left\{F_{n}\left(k_{1}, k_{2}, k_{3}\right)\right\}$, will be cleaved off). All atoms in this union of sets which have positive $\mathbf{a}^{\prime}$ coordinates are removed from the fragments, and the resulting fragments are separated into disjoint fragments using the established algorithm. ${ }^{54}$ The resulting set of fragments constitute the surface fragments, $\left\{G_{n}\left(k_{2}, k_{3}\right)\right\}$. The complete summation in eqn (2.10) is unique. However, note that because the sums in eqn (2.6) are infinite in extent, the labels $\left(k_{1}, k_{2}, k_{3}\right)$ of the original fragments, $F_{n}\left(k_{1}, k_{2}, k_{3}\right)$, can be arbitrarily assigned any integer origin. Of course, the origin of the lattice vectors is also arbitrary. The effect of this arbitrariness is that different choices of labels for the fragments (but completely equivalent when summed) gives different sets $\left\{G_{n}\left(k_{2}, k_{3}\right)\right\}$ and $\left\{F_{n}\left(k_{1}, k_{2}, k_{3}\right)\right\}$ which are also completely equivalent when all the sums in eqn (2.10) are evaluated. It is the whole rhs of eqn (2.10) that is unambiguously defined, not the individual $F_{n}\left(k_{1}, k_{2}, k_{3}\right)$ or $G_{n}\left(k_{2}, k_{3}\right)$.

$\mathrm{Si}(111)$ and $\mathrm{Si}(\mathbf{1 0 0 )}$. A straightforward example of this approach is provided by cleavage of silicon on a (111) plane. Fig. 2(a) depicts the eight atoms which constitute the cubic unit cell with lattice vector lengths of $5.4 \AA$ A. Fig. 2(b) depicts 


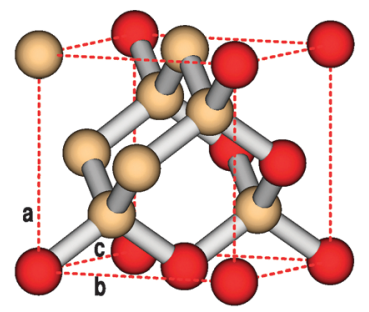

(a)

(b)

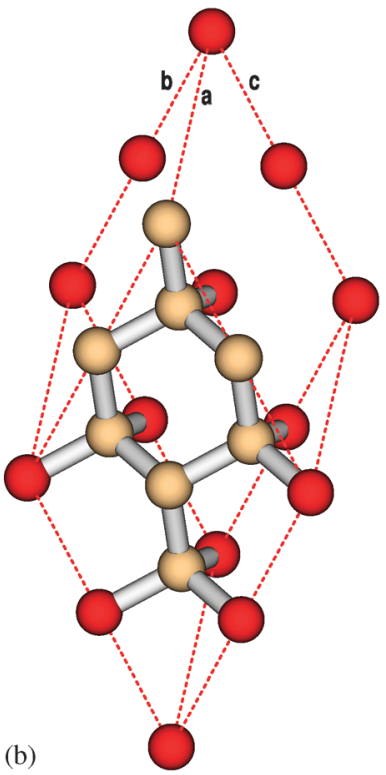

Fig. 2 (a) The cubic unit cell of silicon (diamond structure) is sketched with the eight atoms in one unit cell shown in a lighter colour. (b) A unit cell is sketched which periodically reproduces the crystal structure cleaved along the (111) plane of the structure as represented in (a). The eight atoms in one unit cell are shown in a lighter colour.

the eight atoms which constitute a unit cell in which the first lattice vector is the same as that in Fig. 2(a), but the other two lattice vectors lie in the (111) plane. The supplementary material presents complete lists of the atoms which constitute the $\left\{F_{n}\left(k_{1}, k_{2}, k_{3}\right)\right\}$ and $\left\{G_{n}\left(k_{2}, k_{3}\right)\right\}$, and also the $f_{n}$ and $g_{n}$ of eqn (2.10), for Level 1 and Level 2 fragmentations of the cleaved crystal, along with the definitions and coordinates of the atoms which constitute the unit cell of Fig. 2(b).

For example, at Level 1 both the bulk and surface fragments are $\mathrm{Si}_{2}$ dimers and $\mathrm{Si}$ monomers. In the bulk, there are $16 \mathrm{Si}_{2}$ and $8 \mathrm{Si}$ fragments per unit cell. In the surface layer, there are $12 \mathrm{Si}_{2}$ and $4 \mathrm{Si}$ fragments per surface unit. Individual fragments may be contained within one unit cell, e.g. $\left[\left(2, k_{1}, k_{2}, k_{3}\right)\right.$, $\left.\left(7, k_{1}, k_{2}, k_{3}\right)\right]$ or shared between adjoining unit cells, e.g. $\left[\left(6, k_{1}, k_{2}, k_{3}\right),\left(1, k_{1}-1, k_{2}-1, k_{3}-1\right)\right]$. For Level 2 fragmentation, there are $16 \mathrm{Si}_{5}$ and $8 \mathrm{Si}_{2}$ fragments per unit cell in the bulk crystal; but in the surface there are $4 \mathrm{Si}_{5}, 4 \mathrm{Si}_{4}$ and $12 \mathrm{Si}_{2}$ fragments. The structures of the $\mathrm{Si}_{5}$ and $\mathrm{Si}_{4}$ fragments are sketched in Fig. 3(a). In the established method, when fragments are formed, the "dangling bonds" are "capped" with hydrogen atoms at the appropriate bond length. Hence, an $\mathrm{Si}_{2}$ fragment is actually the disilane molecule, $\mathrm{Si}_{2} \mathrm{H}_{6}$; a monomer $\mathrm{Si}$ fragment is actually the silane molecule, $\mathrm{SiH}_{4}$, and the $\mathrm{Si}_{5}$ and $\mathrm{Si}_{4}$ fragments are neopentasilane and isobutasilane, as sketched in Fig. 3(b). Except for surface fragments, each individual $\mathrm{H}$ atom cap appears in a number of fragments whose coefficients, $f_{n}$ and $g_{n}$ in eqn (2.10), sum to zero. Thus, most $\mathrm{H}$ atom caps "vanish" in the fragmentation expression for the cleaved crystal. The exceptions are the $\mathrm{H}$ atom caps that replace cleaved atoms that were bonded to atoms in the surface, such as the lone $\mathrm{H}$ atom attached to the central $\mathrm{Si}$ atom in the isobutasilane fragment of Fig. 3(b). Hence, in this approach silicon cleaved on the (111) plane is represented by eqn $(2.10)$ as a $\mathrm{Si}(111)$ surface "terminated" by hydrogen atoms. Fig. 4 presents a sketch of a small segment of such a H-terminated $\mathrm{Si}(111)$ surface. It would be a simple matter to remove these surface hydrogen caps or to replace them with other functional groups (in silico, as it were), but herein we are will consider a reaction involving the hydrogen terminated surface.

The supplementary material also presents complete lists of the atoms which constitute the $\left\{F_{n}\left(k_{1}, k_{2}, k_{3}\right)\right\}$ and $\left\{G_{n}\left(k_{2}, k_{3}\right)\right\}$ of eqn (2.10) for Level 1 and Level 2 fragmentations of the crystal cleaved along (100). When the crystal is cleaved on this plane, each of the Si atoms on the top-most surface layer has two "dangling bonds"; that is, each $\mathrm{Si}$ atom is a formal diradical. It is well known that, after cleavage, new $\mathrm{Si}-\mathrm{Si}$ bonds are formed between atoms that are at the 1,5 positions on six-member rings (from which the sixth atom has been cleaved). The presence of these new bonds should be taken into account in evaluating the energy and structure of the surface using the fragmentation approach. Accounting for this additional bonding also requires consideration of the associated change in the surface symmetry and the unit cell. This topic requires more extensive discussion than can be covered herein, so here we limit consideration to the $\mathrm{Si}(111)$ surface for which relaxation or reconstruction is expected to be minimal.

\subsection{PESs and PECSs}

A potential energy surface for a cleaved crystal can be constructed from the fragmentation of eqn (2.10). Just as eqn (2.3) implies eqn (2.4), so the fragmentation of eqn (2.10) implies

$$
\begin{aligned}
E\left(C_{\text {surf }}\right)= & \sum_{k_{1}=-\infty}^{-1} \sum_{k_{2}=-\infty}^{\infty} \sum_{k_{3}=-\infty}^{\infty} \sum_{n=1}^{N_{\text {frag }}} f_{n} E\left[F_{n}\left(k_{1}, k_{2}, k_{3}\right)\right] \\
& +\sum_{k_{2}=-\infty}^{\infty} \sum_{k_{3}=-\infty}^{\infty} \sum_{n=1}^{N_{\text {frag }}^{\text {surf }}} g_{n} E\left[G_{n}\left(k_{2}, k_{3}\right)\right],
\end{aligned}
$$

where $E\left[F_{n}\left(k_{1}, k_{2}, k_{3}\right)\right]$ represents the total electronic energy of fragment $F_{n}\left(k_{1}, k_{2}, k_{3}\right)$, etc. Given that we can calculate this energy for any configuration of $F_{n}\left(k_{1}, k_{2}, k_{3}\right)$ [or similarly $G_{n}\left(k_{2}, k_{3}\right)$ ], then $E\left[F_{n}\left(k_{1}, k_{2}, k_{3}\right)\right]$ represents the complete PES for this fragment (including any $\mathrm{H}$ atom caps). Thus, eqn (2.11) describes an approximation to the complete PES for the cleaved crystal. This approximation is more accurate and more reliable the higher the level of fragmentation employed.

Note that although the periodicity of a crystal structure was used to derive eqn (2.10) and (2.11), the energy of the cleaved crystal can be evaluated, in principle, for any structure. Of course, if we distort the crystal structure sufficiently so as to re-arrange the chemical bonding, then eqn (2.11) would not be a very accurate PES. Nonetheless, the PES of eqn (2.11) might be sufficiently accurate in many applications. Quantitative evidence for this assertion will be presented below.

Aside: It is important to recall that only relative energies, or energies per unit volume, or unit surface area are relevant, not total energies. Thus, when considering any process taking place on the surface of a cleaved crystal, the structure of the crystal far below the surface could be considered to be the 

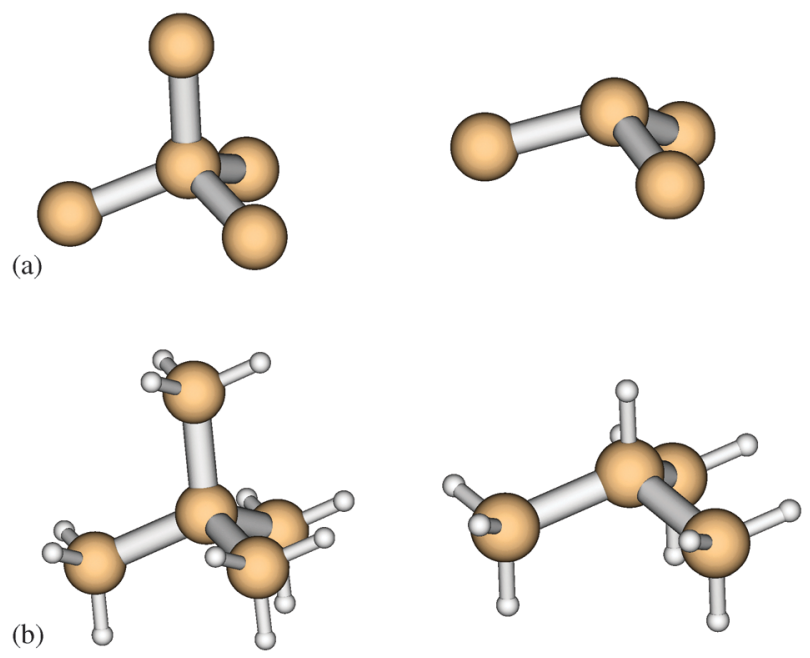

Fig. 3 (a) $\mathrm{Si}_{5}$ and $\mathrm{Si}_{4}$ fragments which arise from the surface layer in Level 2 fragmentation of a $\mathrm{Si}(111)$ surface are sketched. (b) The fragments in (a) are shown with the $\mathrm{H}$ atom caps attached.

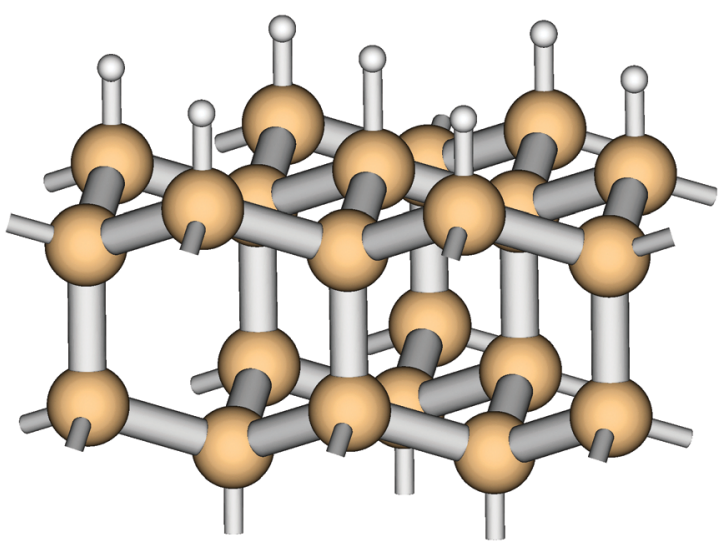

Fig. 4 A small section of a hydrogen atom terminated $\mathrm{Si}(111)$ surface is sketched, showing the pattern of hydrogen atoms bonded to $\mathrm{Si}$ atoms which are bonded to three other $\mathrm{Si}$ atoms in the surface layer.

same as that of the bulk crystal. Hence, the energies of the fragments far from the surface can be ignored in eqn (2.11) as part of a reference energy. Similarly, if a surface process is sufficiently dilute on the surface, surface fragments far from the site of the process have the same structure as in the unperturbed surface, and their energies can also be incorporated in the reference energy. Hence, in practice, one is always only concerned with evaluating a finite relative energy, approximated by a finite subset of the fragment energies in eqn (2.11). Similarly, the "surface energy" of a cleaved surface is a finite number per unit surface area, expressed in terms of the difference in energy between bulk and surface fragment energies.

Different PESs are represented by eqn (2.11) for different levels of fragmentation. In general (and in the example above), the number of atoms in the fragments increases as the level of fragmentation increases. Hence, the dimensionality of the associated PES increases accordingly. It has been demonstrated in the molecular context ${ }^{36}$ that a significant computational advantage in the evaluation of such a hierarchy of PESs can be obtained by considering the following form:

$$
\begin{aligned}
E\left(C_{\text {surf }}\right) \equiv & E\left(C_{\text {surf }}^{\text {Level1 }}\right) \\
& +E\left(C_{\text {surf }}^{\text {Level2 }}\right)-E\left(C_{\text {surf }}^{\text {Level1 }}\right) \\
& +E\left(C_{\text {surf }}^{\text {Level3 }}\right)-E\left(C_{\text {surf }}^{\text {Level2 }}\right) \\
& +\cdots
\end{aligned}
$$

Eqn (2.12) is a tautology, because when the level of fragmentation is infinitely large, the crystal (and cleaved surface) is not fragmented at all, and the exact energy results. The first line on the rhs of eqn (2.12) represents a PES, as in eqn (2.11). However, the second line is only a potential energy correction surface (PECS). It denotes the energy difference between Level 2 and Level 1 approximations to the PES. It has been extensively demonstrated, ${ }^{54}$ that the energy difference between Level 1 and Level 2 approximations to molecular electronic energies is small, the difference between Level 2 and Level 3 approximations is smaller still, and so on. During a chemical reaction, for example, the molecular structure changes substantially, and the energy may change by hundreds of $\mathrm{kJ} \mathrm{mol}^{-1}$. Similarly, for a reaction occurring on a cleaved surface, the PES, $E\left(C_{\text {surf }}^{\text {Level1 }}\right)$, may vary by hundreds of $\mathrm{kJ} \mathrm{mol}^{-1}$. However, the PECS, $E\left(C_{\text {surf }}^{\text {Level2 }}\right)-E\left(C_{\text {surf }}^{\text {Level1 }}\right)$, may only vary by a few $\mathrm{kJ} \mathrm{mol}^{-1}$. A quantitative example of this point in the molecular context was reported for the reaction of hydrogen and $n$-pentane. ${ }^{36}$ The important point is that a PECS is a relatively "flat" function. A Level 1 PES may need to describe a large energy range, but is relatively low in dimensionality; sufficiently low that methods are available to construct such PESs. PECSs like $E\left(C_{\text {surf }}^{\text {Level2 }}\right)-E\left(C_{\text {surf }}^{\text {Level1 }}\right)$ are high in dimensionality, but are flat. It is a much easier computational task to accurately describe a high dimensional flat surface than a high dimensional surface that varies substantially.

\section{Application to $\mathrm{H}+\mathrm{H}-\mathrm{Si}(111)$}

The fragmentation procedure described above produces a $\mathrm{Si}(111)$ surface that is terminated with hydrogen atoms, as sketched in Fig. 4. The fragmentation approximation to the PES for a hydrogen atom colliding with this surface is given by a simple modification of eqn (2.11):

$$
\begin{aligned}
E\left(H+C_{\text {surf }}\right)= & \sum_{k_{1}=-\infty}^{-1} \sum_{k_{2}=-\infty}^{\infty} \sum_{k_{3}=-\infty}^{\infty} \sum_{n=1}^{N_{\text {frag }}} f_{n} E\left[H+F_{n}\left(k_{1}, k_{2}, k_{3}\right)\right] \\
& +\sum_{k_{2}=-\infty}^{\infty} \sum_{k_{3}=-\infty}^{\infty} \sum_{n=1}^{N_{\text {frag }}^{\text {surf }}} g_{n} E\left[H+G_{n}\left(k_{2}, k_{3}\right)\right] .
\end{aligned}
$$

That is, each fragment PES in eqn (2.11) is simply replaced by the PES for a hydrogen atom colliding with that fragment. Note that the coordinates of the $\mathrm{H}$ atom are the same in every PES, while the coordinates of the other atoms in the fragments depend on $\left(k_{1}, k_{2}, k_{3}\right)$. At Level 1 , these are simply the PESs for $\mathrm{H}+\mathrm{SiH}_{4}$ and $\mathrm{H}+\mathrm{Si}_{2} \mathrm{H}_{6}$. As noted in the aside above, we can neglect a constant reference energy in both eqn (2.11) and (3.1), conveniently taken in (3.1) as the energy where the 
Table 1 Energies $\left(\mathrm{kJ} \mathrm{mol}^{-1}\right)$ of products and saddle points, relative to reactants, are shown for primary $(p)$, secondary $(s)$ and tertiary $(t)$ silane radicals, reactions (3.4)-(3.6), for the aug-cc-pVDZ basis set. Geometries for (3.4) and (3.5) were optimised for the MP2 "exact" calculations. Geometries for (3.6) are described in the text. The exact values are compared with the corresponding Level 1 approximations (see text)

\begin{tabular}{llll}
\hline & & Hartree Fock & MP2 \\
\hline Products & & & \\
$\mathrm{H}_{2}+\mathrm{Si}_{3} \mathrm{H}_{7}(p)$ & Exact & -41.71 & -53.40 \\
& Level 1 & -42.02 & -53.79 \\
$\mathrm{H}_{2}+\mathrm{Si}_{3} \mathrm{H}_{7}(s)$ & Exact & -51.87 & -63.11 \\
& Level 1 & -52.26 & -64.23 \\
$\mathrm{H}_{2}+\mathrm{Si}_{4} \mathrm{H}_{9}(t)$ & Exact & -61.06 & -70.94 \\
& Level 1 & -64.25 & -75.21 \\
$\mathrm{H}_{2}+\mathrm{Si}_{22} \mathrm{H}_{27}(t)$ & Exact & -74.19 & - \\
$\mathrm{Saddle} \mathrm{points}$ & Level 1 & -74.06 & - \\
$\mathrm{H} \cdots \mathrm{H} \cdots \mathrm{Si}_{3} \mathrm{H}_{7}(p)$ & & & \\
& Exact & 53.28 & 28.52 \\
$\mathrm{H} \cdots \mathrm{H} \cdots \mathrm{Si}_{3} \mathrm{H}_{7}(s)$ & Level 1 & 53.66 & 29.46 \\
& Exact & 49.64 & 25.33 \\
$\mathrm{H} \cdots \mathrm{H} \cdots \mathrm{Si}_{4} \mathrm{H}_{9}(t)$ & Level 1 & 48.94 & 24.50 \\
& Exact & 45.65 & 21.73 \\
$\mathrm{H} \cdots \mathrm{H} \cdots \mathrm{Si}_{22} \mathrm{H}_{27}(t)$ & Level 1 & 45.84 & 21.89 \\
& Exact & 43.99 & - \\
\hline & Level 1 & 44.82 & - \\
\hline
\end{tabular}

$\mathrm{H}$ atom is infinitely distant from the cleaved crystal (which is at some fixed geometry). Relative to this reference energy, eqn (3.1) accounts for the interaction energy of a single $\mathrm{H}$ atom with every atom in the cleaved crystal.

The important question is whether this approach can produce a potential energy surface that is sufficiently accurate; accurate enough that dynamical studies can provide an accurate description of the reaction. Here we present evidence that indicates the accuracy of the Level 1 approximation for $\mathrm{H}+\mathrm{H}-\mathrm{Si}(111)$.

At Level 1, the PES for reaction of $\mathrm{H}$ atoms with the cleaved crystal is given in terms of the PESs for the following reactions:

$$
\begin{gathered}
\mathrm{H}+\mathrm{SiH}_{4} \rightarrow \mathrm{H}_{2}+\mathrm{SiH}_{3} \\
\mathrm{H}+\mathrm{Si}_{2} \mathrm{H}_{6} \rightarrow \mathrm{H}_{2}+\mathrm{Si}_{2} \mathrm{H}_{5}
\end{gathered}
$$

We denote these PESs as $E\left(\mathrm{H}+\mathrm{SiH}_{4}\right)$ and $E\left(\mathrm{H}+\mathrm{Si}_{2} \mathrm{H}_{6}\right)$. The next larger analogues of these reactions involve trisilane:

$$
\begin{gathered}
\mathrm{H}+\mathrm{SiH}_{3} \mathrm{SiH}_{2} \mathrm{SiH}_{3} \rightarrow \mathrm{H}_{2}+\mathrm{SiH}_{2} \mathrm{SiH}_{2} \mathrm{SiH}_{3}, \\
\rightarrow \mathrm{H}_{2}+\mathrm{SiH}_{3} \mathrm{SiHSiH}_{3},
\end{gathered}
$$

where both primary and secondary radicals may be formed. At Level 1 fragmentation, $\mathrm{SiSiSi} \rightarrow \mathrm{SiSi}+\mathrm{SiSi}-\mathrm{Si}$, so that $\mathrm{H}+\mathrm{SiSiSi} \rightarrow(\mathrm{H}+\mathrm{SiSi})+(\mathrm{H}+\mathrm{SiSi})-(\mathrm{H}+\mathrm{Si})$. Table 1 presents the energies of the saddle points and products for both primary and secondary radical formation in eqn (3.4), relative to the reactant energy, compared to the corresponding Level 1 approximation. The geometries of all species are those optimised at the MP2/aug-cc-pVDZ level of $a b$ initio theory for the whole (non-fragmented) molecule. Results are shown for both Hartree-Fock and MP2 calculations. Extensive calculations of errors in the fragmentation approximation in gas phase molecules has established that the fragmentation error does not depend significantly on the ab initio method employed. ${ }^{34,35}$ The corresponding comparison for the formation of the tertiary radical in isobutasilane,

$$
\mathrm{H}+\left(\mathrm{SiH}_{3}\right)_{3} \mathrm{SiH} \rightarrow \mathrm{H}_{2}+\left(\mathrm{SiH}_{3}\right)_{3} \mathrm{Si},
$$

is also shown in Table 1. A tertiary radical is also formed from reaction of a $\mathrm{H}$ atom with the cluster shown in Fig. 4 (with all dangling bonds capped with $\mathrm{H}$ atoms), which represents part of the H-terminated $\mathrm{Si}(111)$ surface:

$$
\mathrm{H}+\mathrm{Si}_{22} \mathrm{H}_{28} \rightarrow \mathrm{H}_{2}+\mathrm{Si}_{22} \mathrm{H}_{27}
$$

Table 1 also compares the ab initio saddle point and product energies with the corresponding Level 1 approximation for this cluster. The geometry of this cluster is that given by fragmentation of the standard crystal structure (a cubic diamond structure with a lattice constant of $5.42 \AA$ ), except that the breaking $\mathrm{Si}-\mathrm{H}$ and forming $\mathrm{H}-\mathrm{H}$ bond lengths at the

\begin{tabular}{|c|c|c|c|c|}
\hline & $\mathrm{H} \cdots \mathrm{H}-\mathrm{SiH}_{3}$ & $\mathrm{H}_{2}+\mathrm{SiH}_{3}$ & $\mathrm{H} \cdots \mathrm{H}-\mathrm{Si}_{2} \mathrm{H}_{5}$ & $\mathrm{H}_{2}+\mathrm{Si}_{2} \mathrm{H}_{5}$ \\
\hline $\mathrm{UHF} / 6-31 \mathrm{G}(\mathrm{d}) / / \mathrm{MP}^{a}{ }^{a}$ & 68.8 & -25.1 & 62.9 & -37.2 \\
\hline UHF/aug-cc-pVDZ//MP2 & 59.6 & -31.8 & 54.3 & -42.0 \\
\hline UHF/aug-cc-pVTZ//MP2 & 61.5 & -34.3 & 55.7 & -45.5 \\
\hline B3LYP/aug-cc-pVDZ & 3.8 & -58.8 & 2.1 & -70.8 \\
\hline B3LYP/aug-cc-pVTZ & 4.9 & -64.7 & $-b$ & -77.8 \\
\hline M05-2X/aug-cc-pVDZ & 23.3 & -44.9 & 21.2 & -57.6 \\
\hline M05-2X/aug-cc-pVTZ & - & -54.1 & 22.5 & -68.1 \\
\hline $\mathrm{UMP} 2 / 6-31 \mathrm{G}(\mathrm{d})$ & 57.4 & -34.9 & 51.1 & -46.9 \\
\hline UMP2/aug-cc-pVDZ & 34.7 & -43.4 & 29.6 & -53.8 \\
\hline UMP2/aug-cc-pVTZ & 33.8 & -46.8 & 28.4 & -58.8 \\
\hline QCISD/mixed & 27.7 & -62.9 & 23.4 & -72.9 \\
\hline QCISD/6-31G(d,3p) & 27.7 & -59.2 & 23.4 & -71.7 \\
\hline QCISD/aug-cc-pVDZ & 23.6 & -55.0 & 19.4 & -66.2 \\
\hline QCISD/aug-cc-pVTZ & 23.1 & -57.7 & 18.8 & -70.4 \\
\hline $\operatorname{CCSD}(\mathrm{T}) / 6-31 \mathrm{G}(\mathrm{d}) / / \mathrm{MP} 2$ & 45.9 & -46.7 & 40.4 & -58.6 \\
\hline CCSD(T)/aug-cc-pVDZ//MP2 & 21.1 & -54.1 & 16.6 & -65.3 \\
\hline CCSD(T)/aug-cc-pVTZ//MP2 & 20.1 & -56.5 & 15.4 & -69.2 \\
\hline
\end{tabular}
saddle point are taken from the corresponding values for reaction (3.5). As Table 1 shows, the Level 1 approximation describes the saddle point energies for these primary, secondary

Table 2 Ab initio energies $\left(\mathrm{kJ} \mathrm{mol}^{-1}\right)$ for the stationary point geometries along $\mathrm{H}_{2}$ abstraction paths for $\mathrm{SiH}_{4}+\mathrm{H}$ and $\mathrm{Si}_{2} \mathrm{H}_{6}+\mathrm{H}_{\text {, relative to }}$ reactants, are shown for various levels of ab initio theory

$a$ " //MP2" indicates that the geometry was optimised with the given basis set, at the MP2 level of theory. ${ }^{b}$ Blank entries indicate that no stationary point was found. 
and tertiary radical formations to within about $1 \mathrm{~kJ} \mathrm{~mol}^{-1}$, and calculates the reaction energy to within a few $\mathrm{kJ} \mathrm{mol}^{-1}$. Hence, we might reasonably take the Level 1 PES of eqn (3.1) as an adequate starting point for a description of the energetics for reaction of $\mathrm{H}$ with $\mathrm{H}$-terminated $\mathrm{Si}(111)$.

\section{PESs for $\mathrm{H}+\mathrm{SiH}_{4}$ and $\mathrm{H}+\mathrm{Si}_{2} \mathrm{H}_{6}$}

\subsection{Ab initio molecular orbital theory calculations}

Before ab initio calculations can be performed to construct the PES, an appropriate level of theory must be selected. As an indication of the accuracy of a particular level of $a b$ initio calculation, we have considered the energies of the abstraction saddle points and products, relative to that of the reactants. All calculations were performed with the GAUSSIAN 09 program. $^{56}$ Table 2 shows the calculated saddle point and product energies, relative to reactants, for reactions (3.2) and (3.3), for various levels of theory. No zero point vibrational energies are included in these values. We assume that the most reliable estimate of these energies is given by the $\operatorname{CCSD}(\mathrm{T}) /$ aug-cc-pVTZ//MP2 calculations.

It is clear that the Hartree-Fock and B3LYP methods perform poorly for these systems. Similarly, UMP2 tends to overestimate barrier heights and underestimate reaction energies. The M05-2X hybrid density functional ${ }^{57}$ appears to perform quite well. However, on closer examination, it is revealed that the optimised geometries were substantially different for this functional than for the other methods considered. Furthermore, calculations along the $\mathrm{H}+\mathrm{Si}_{2} \mathrm{H}_{6} \rightarrow$ $\mathrm{H}_{2}+\mathrm{Si}_{2} \mathrm{H}_{5}$ reaction path indicated that the M05-2X intermolecular interaction was far too long-ranged, yielding a "too wide" barrier energy profile: When the incoming $\mathrm{H}$ atom was $2.4 \AA$ from the target $\mathrm{H}$ atom, the M05-2X energy was $9 \mathrm{~kJ} \mathrm{~mol}^{-1}$ higher than the reactant state, compared to $0.1 \mathrm{~kJ} \mathrm{~mol}^{-1}$ for a $\operatorname{CCSD}(\mathrm{T})$ calculation.

Construction of a complete PES for these systems requires evaluation of energies, gradients and Hessians at hundreds or thousands of molecular configurations. To facilitate construction of the PESs in this first application to moleculesurface reaction, we determined a level of theory which provides reasonable accuracy at low computational cost. The QCISD level of theory conveniently provides fast "analytic" gradients and reasonable accuracy compared to the CCSD(T) method. It was determined that the energies along an abstraction reaction path for $\mathrm{H}+\mathrm{Si}_{2} \mathrm{H}_{6}$ were most sensitive to the nature of the basis functions centred on the hydrogen atoms; the quality of the silicon-atom-centred basis had little effect. A mixed basis set, 6-31G(d,2p) on hydrogen atoms and 3-21G on silicon atoms, with the QCISD method, produced the "QCISD/mixed" results shown in Table 2, at reasonable computational cost. This level of theory has been used herein to produce the PESs.

\subsection{Constructing the potential energy surfaces}

The PESs for reactions of hydrogen atoms with silane and disilane have been computed as modified Shepard interpolations over a data set of ab initio points using the Grow methodology. The details of the Grow methodology have been presented previously, ${ }^{6-8,58-60}$ so only a brief description shall be given here.

The potential energy at some molecular configuration $Z$ is given by the expression:

$$
E(Z)=\sum_{g \in G} \sum_{i=1}^{N_{\text {data }}} w_{g \circ i}(Z) T_{g \circ i}(Z)
$$

In this equation, the sum over $i$ iterates over the $N_{\text {data }}$ geometries ("data points") at which ab initio calculations have been performed to evaluate the potential energy and its first and second derivatives. The $T$ are second order Taylor series expansions for the energy around each data point. The subscript $g \circ i$ denotes that the quantity is evaluated for a permutation $g$ of data point $i$. $G$ is the symmetry group of the molecule, most generally the complete nuclear permutation (CNP) group. The sum over $G$ means that all permutationally equivalent geometries are included in the data set, so the interpolated potential obeys the underlying permutation symmetry. In this work the CNP group of $120 \mathrm{H}$ atom permutations was used for the $\mathrm{SiH}_{5} \mathrm{PES}$. For $\mathrm{Si}_{2} \mathrm{H}_{7}$ a more restricted set of 504 permutations was used, excluding swaps of $\mathrm{H}$ atoms from one $\mathrm{Si}$ to the other, which are considered to be unfeasible. The quantity $w$ is a normalised weight function that is constructed to ensure an interpolation of the $a b$ initio data. In this work we used the "two part" weight function defined in ref. 7 with parameter values: $E_{\mathrm{tol}}=2 \times 10^{-4} \mathrm{~m} E_{\mathrm{h}}$, $M=48, q=2$, and $p=8$ for $\mathrm{SiH}_{5}$ and $p=13$ for $\mathrm{Si}_{2} \mathrm{H}_{7}$.

Starting from a PES defined by an initial set of data points distributed along the minimum energy path of the relevant $\mathrm{H}+\mathrm{HX} \rightarrow \mathrm{H}_{2}+\mathrm{X}$ reaction, configuration space was explored using quasiclassical trajectories (QCT). The QCT calculations were performed with a version of VENUS $96^{61}$ modified to use a modified-Shepard-interpolated PES. ${ }^{62,63}$ The trajectories were integrated according to the classical equations of motion with a velocity-verlet integrator using a time step of $0.01 \mathrm{au}$.

Geometries were selected to be added to the ab initio data set based upon estimates of the accuracy of the interpolated potential along the paths traced by the trajectories. Geometries were selected alternating between " $h$-weight" and "variance" criteria. 8,44 Periodically, after adding one or two hundred more data points to the data set, larger batches of trajectories were evaluated to assess the reaction probability according to the current interpolated PES. The process was iterated until the calculated reaction probability was deemed sufficiently converged, indicating that dynamically-relevant regions of the interpolated PES were determined accurately.

\section{3 $\mathrm{H}+\mathrm{SiH}_{4} \rightarrow \mathrm{H}_{2}+\mathrm{SiH}_{3}$}

For the $\mathrm{SiH}_{5} \mathrm{PES}$, an initial set of 76 data points was used. These points were selected from an IRC calculation ${ }^{64}$ starting from the $\mathrm{H} \cdots \mathrm{H}-\mathrm{SiH}_{3}$ saddle point and represent the minimum energy path (MEP) between the $\mathrm{H}+\mathrm{SiH}_{4}$ and $\mathrm{H}_{2}+\mathrm{SiH}_{3}$ configurations.

During the construction of a PES with the Grow procedure, the classical trajectories are conventionally set up with the reactants selected from a microcanonical ensemble with at least the harmonic zero point energy (ZPE) as the total vibrational energy. However, in this case, the intended 
application is for adatoms interacting with a crystalline substrate. It is likely that this substrate crystal will be treated as a frozen lattice. Even were that not so, the range of $\mathrm{Si}-\mathrm{Si}$ distances and bonding angles sampled by populating zero point or finite-temperature phonons is likely to be substantially smaller than the range of $\mathrm{Si}-\mathrm{H}$ distances and bonding angles sampled by zero point motion in $\mathrm{SiH}_{4}$. In light of this, we constructed two independent PESs for the $\mathrm{SiH}_{5}$ system. One (PES1) was constructed sampling geometries from trajectories including $31.7 \mathrm{~m} E_{\mathrm{h}}\left(83.2 \mathrm{~kJ} \mathrm{~mol}^{-1}\right)$ of initial $\mathrm{ZPE}$ in the $\mathrm{SiH}_{4}$ molecule. A second (PES2) was constructed where no initial internal motion was incorporated in the $\mathrm{SiH}_{4}$ molecule before the collision with $\mathrm{H}$. The effective dimension of the region of configuration space sampled by the trajectories without ZPE was expected to be lower, suggesting that the PES should converge more quickly. For sampling, trajectories were integrated with an initial relative translational energy of $40 \mathrm{~m} E_{\mathrm{h}}\left(105 \mathrm{~kJ} \mathrm{~mol}^{-1}\right)$, an impact parameter of zero and initial fragment centre of mass separation of $25 \mathrm{a}_{0}(13.2 \AA)$. Similar parameters were used for the larger batches of trajectories to evaluate the reaction cross sections, except that the impact parameters were selected from a linear distribution up to a maximum impact parameter $b_{\text {max }}$ of $6 \mathrm{a}_{0}(3.2 \AA)$.

We note that even for PES2, the data set is not dominated by near-equilibrium $\mathrm{SiH}_{4}$ geometries. During the PES construction, non-reactive trajectories exhibited a distinct tendency to transfer around $20 \mathrm{~m} E_{\mathrm{h}}$ of the $40 \mathrm{~m} E_{\mathrm{h}}$ translational energy into internal motion of $\mathrm{SiH}_{4} . \mathrm{SiH}_{4}$ geometries away from the initial, potential minimum configuration, accessed with this transferred energy, were favoured by the geometry selection procedures.

The Grow process was paused periodically to run a larger batch of trajectories to calculate reaction cross sections using the current interpolated PES. From a set of $N_{\mathrm{t}}$ trajectories producing $N_{\mathrm{r}}$ reaction events, the reactive cross section is given by

$$
\sigma(E)=\pi b_{\max }^{2}\left(N_{\mathrm{r}} / N_{\mathrm{t}}\right)
$$

where $b_{\max }$ is the maximum impact parameter. As this set represents a finite sampling of the desired ensemble, uncertainties in the determination of this value have been calculated as $95 \%$ Wilson score confidence intervals. ${ }^{65}$

Batches of typically 4000 trajectories were run at initial relative translational energies of $40 \mathrm{~m} E_{\mathrm{h}}\left(105 \mathrm{~kJ} \mathrm{~mol}^{-1}\right)$ and $20 \mathrm{~m} E_{\mathrm{h}}\left(52.5 \mathrm{~kJ} \mathrm{~mol}^{-1}\right)$. The resulting reactive cross sections for the reaction in eqn (3.2), using PES2, are shown in Fig. 5. Clearly, the calculated cross sections were essentially converged after adding 700-900 data points to the interpolation. For PES2, the reaction probabilities showed little structure as a function of impact parameter. For both collision energies in Fig. 5, the probability was relatively constant for impact parameters from zero to about 2.5-3 $\mathrm{a}_{0}$, before smoothly dropping to zero. No reactive trajectories were observed at impact parameters greater than 4.5 and $3 \mathrm{a}_{0}$ for collisions at 40 and $20 \mathrm{~m} E_{\mathrm{h}}$, respectively.

The corresponding results for PES1 are shown in Fig. 6 as a function of the number of data points. Including ZPE increased the reaction probability and slightly increased the variability in the calculated cross sections for different numbers of data points.

As a further test of the convergence of the interpolated PES as a function of the number of data points, the interpolated PES energy was compared to ab initio calculated energies for a representative set of geometries. These geometries were selected from a batch of trajectories simulating $\mathrm{H}+\mathrm{SiH}_{4}$ collisions at a relative energy of $40 \mathrm{~m} E_{\mathrm{h}}\left(105 \mathrm{~kJ} \mathrm{~mol}^{-1}\right)$. No ZPE was included in the $\mathrm{SiH}_{4}$ molecule. The trajectories were run on PES2, defined by 900 data points that had been grown without ZPE. A total of 500 geometries were selected. As the reaction probability is quite low, to ensure the product channel was adequately represented 200 points were selected at random from geometries with a hydrogen-hydrogen distance of less than $0.9 \AA$. The remaining points were selected at random without bias. $A b$ initio calculations were then performed on this set of geometries to provide reference energies. The mean deviation between the correct $a b$ initio energies and the energies given by the interpolated PES, as a function of the number of data points in the interpolated PES, is shown in Fig. 7. For the PES grown without including ZPE, the mean error decreased very nearly monotonically, to be smaller than $0.08 \mathrm{~m} E_{\mathrm{h}}$ for the 1400 point data set. This compares to a total range of the energies of the selected geometries of $55 \mathrm{~m} E_{\mathrm{h}}$. The mean absolute error for the same set of geometries was also calculated with PES1 (grown with ZPE included in the initial $\mathrm{SiH}_{4}$ state). The average error was substantially higher for this PES, hovering around $0.3 \mathrm{~m} E_{\mathrm{h}}$ for interpolated PESs of greater than about 1000 data points, as shown in Fig. 7. This probably reflects the fact that PES1 was constructed at much higher energy than that used to sample the interpolation error, requiring extrapolation to regions where the PES1 data set is sparse.

Trajectory simulations were carried out using both PES1 and PES2. Batches of 4000-5000 trajectories were calculated with specific initial collision energies. Batches of trajectories with ZPE initially contained in the $\mathrm{SiH}_{4}$ molecule were run with the PES grown with ZPE included, and correspondingly batches without ZPE were run on the PES grown without ZPE. Additionally, batches of trajectories not incorporating initial ZPE in $\mathrm{SiH}_{4}$ were run using the PES grown with ZPE included. The results are shown in Fig. 8.

When ZPE is included in the reactants, the results here are in reasonable agreement with the trajectory calculations of Cao et al., ${ }^{66}$ evaluated on a much higher level ab initio PES. The cross sections initially rise with increasing energy, but become approximately constant at high energy.

The calculated cross sections are smaller when $\mathrm{SiH}_{4}$ has no initial vibrational energy. Apparently, the ZPE can contribute to crossing the reaction barrier. Cao et al. applied one of the several possible corrections designed for a better treatment of ZPE effects by discarding all trajectories with internal energies of the final fragments below that of the relevant ZPE level. They found a decrease in the calculated cross sections in the vicinity of $25 \%$, yielding cross sections not far above those calculated here with no ZPE.

When no ZPE is included initially, the calculated cross sections exhibit a tendency to decrease at high translational energy. Some caution should be exercised at high collision 


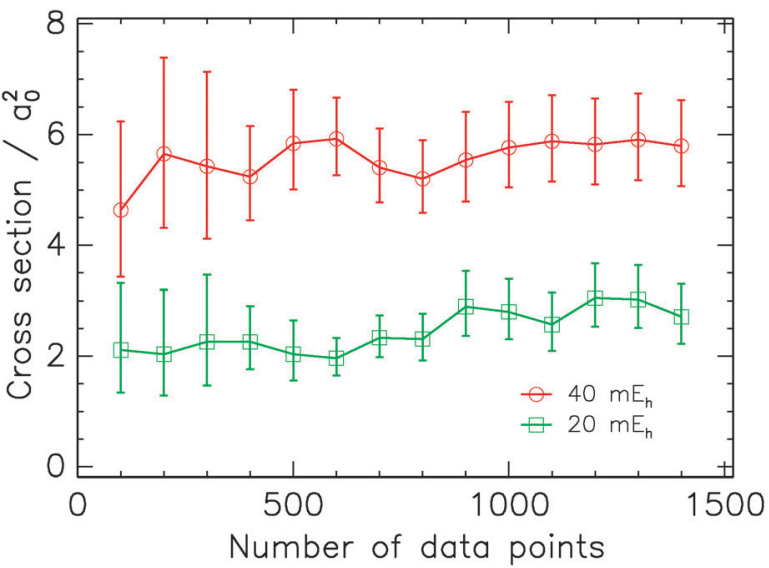

Fig. 5 Reaction cross sections for $\mathrm{H}+\mathrm{SiH}_{4}$ are shown as a function of the number of data points in PES2. Results are shown for initial relative translational energies of $40 \mathrm{~m} E_{\mathrm{h}}\left(105 \mathrm{~kJ} \mathrm{~mol}^{-1}\right)$ and $20 \mathrm{~m} E_{\mathrm{h}}$ $\left(52.5 \mathrm{~kJ} \mathrm{~mol}^{-1}\right) .95 \%$ confidence intervals are indicated.

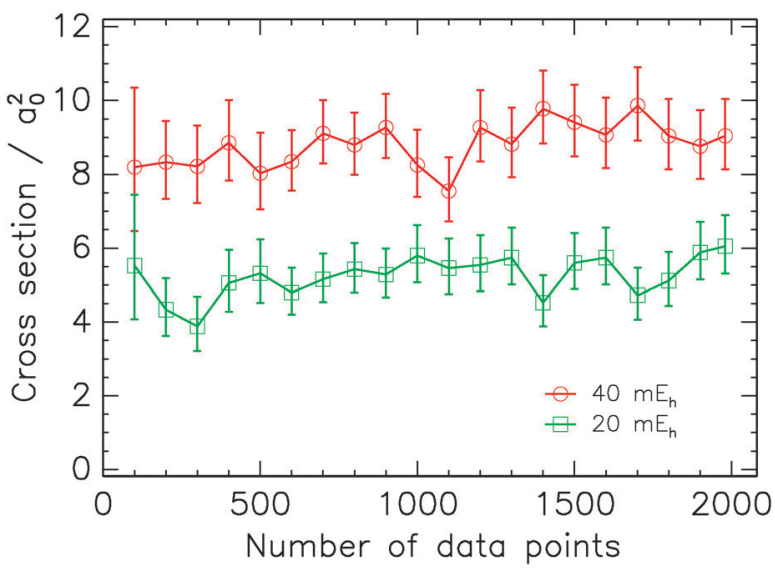

Fig. 6 Reaction cross sections for $\mathrm{H}+\mathrm{SiH}_{4}$ are shown as a function of the number of data points in PES1. Results are shown for initial relative translational energies of $40 \mathrm{~m} E_{\mathrm{h}}\left(105 \mathrm{~kJ} \mathrm{~mol}^{-1}\right)$ and $20 \mathrm{~m} E_{\mathrm{h}}$ $\left(52.5 \mathrm{~kJ} \mathrm{~mol}^{-1}\right)$, and an initial vibrational energy in $\mathrm{SiH}_{4}$ of $31.7 \mathrm{~m} E_{\mathrm{h}}$ $\left(83.2 \mathrm{~kJ} \mathrm{~mol}^{-1}\right)$, which approximates the ZPE. 95\% confidence intervals are indicated.

energies, as the accuracy of the interpolated PES at energies above that used when selecting data points is expected to be reduced. However, adding another 80 data points by growing at a collision energy of $60 \mathrm{~m} E_{\mathrm{h}}$ does not alter the calculated cross section for this energy, so the decrease in cross section at higher energies should not be attributed to such an inaccuracy. Rather, this may be an internal energy transfer limitation, similar to that observed in the $\mathrm{H}+\mathrm{CD}_{4}$ reaction. ${ }^{67}$

To confirm this interpretation, a number of slices through the "reaction probability function" were investigated. With no ZPE there is no initial vibrational energy distribution and phase. Hence the outcome of each trajectory becomes a function of only three angles, the impact parameter and the collision energy. Trajectories were calculated for each point in a grid over impact parameter and an angle at three energies $\left(20,40\right.$ and $\left.60 \mathrm{~m} E_{\mathrm{h}}\right)$ and three different $\mathrm{SiH}_{4}-\mathrm{H}$ orientations (the initial $\mathrm{H}$ velocity parallel to an $\mathrm{Si}-\mathrm{H}$ bond on the $\mathrm{H}$ side, on the $\mathrm{Si}$ side and parallel to a line bisecting $\mathrm{H}-\mathrm{Si}-\mathrm{H}$ ).

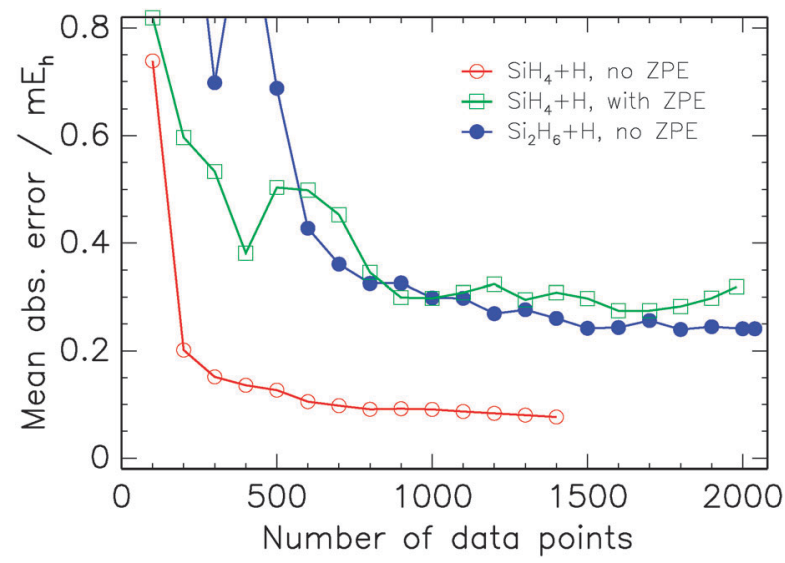

Fig. 7 Mean absolute error (absolute difference between the ab initio energy and the interpolated PES energy) for a sample of geometries (see text for details) are shown as a function of the number of data points defining the PES. Results are shown for $\mathrm{H}+\mathrm{SiH}_{4}$ using PES2 (no ZPE) and PES1 (with ZPE), and for $\mathrm{H}+\mathrm{Si}_{2} \mathrm{H}_{6}$.

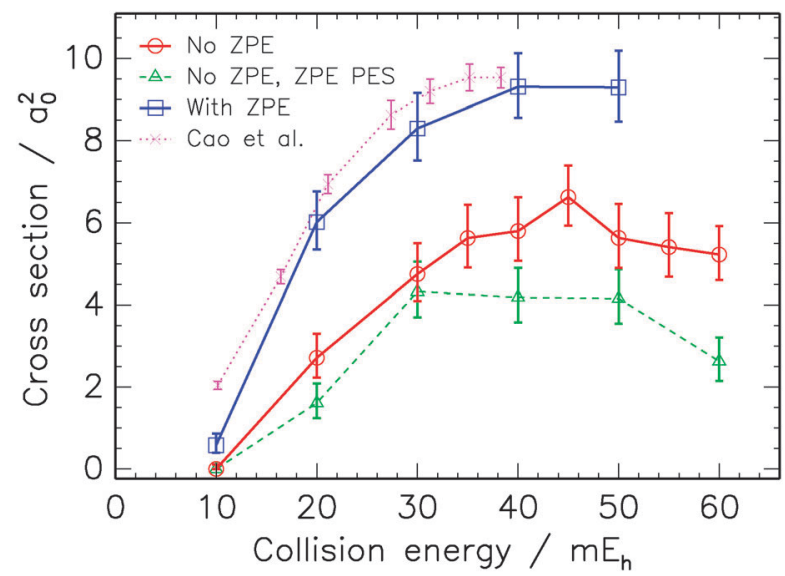

Fig. 8 Calculated reaction cross sections for $\mathrm{H}+\mathrm{SiH}_{4} \rightarrow \mathrm{H}_{2}+\mathrm{SiH}_{3}$ are shown as a function of the translational collision energy. Results are shown for PES1 (with ZPE) with an initial vibrational energy in $\mathrm{SiH}_{4}$ of $31.7 \mathrm{~m} E_{\mathrm{h}}\left(83.2 \mathrm{~kJ} \mathrm{~mol}^{-1}\right)$; for PES2 (no ZPE) with no initial vibrational energy in $\mathrm{SiH}^{4}$; and for PES1 with no initial vibrational energy in $\mathrm{SiH}_{4}$ (no ZPE, ZPE PES). Results from Cao et al. ${ }^{66}$ are also shown. $95 \%$ confidence intervals are indicated.

An illustrative slice is shown in Fig. 9, with regions coloured according to the fate of trajectories initially aimed at each point with the initial velocity perpendicular to the page.

When the $\mathrm{H}$ atom interacts directly with the $\mathrm{Si}$ atom, various $\mathrm{H}$ atom exchange processes occur. These are some of the mechanisms identified by $\mathrm{Cao}$ et al. $\mathrm{H}$ atom exchange was distinctly favoured if the incoming $\mathrm{H}$ atom collided with the $\mathrm{SiH}_{4}$ in the vicinity of the $\mathrm{H}-\mathrm{Si}-\mathrm{H}$ plane of nearby hydrogens (the horizontal axis in Fig. 9). Similar behaviour was observed at other orientations. Like the $\mathrm{H}+\mathrm{CD}_{4}$ reaction, ${ }^{67}$ the "cone of acceptance" for the abstraction reaction (and, indeed, the exchange reaction) increased as the collision energy was increased. At elevated collision energies, this was accompanied by the growth of a "cone of rejection" for trajectories with direct $\mathrm{H}-\mathrm{H}$ collisions, where the incoming hydrogen atom rebounded off the repulsive part 


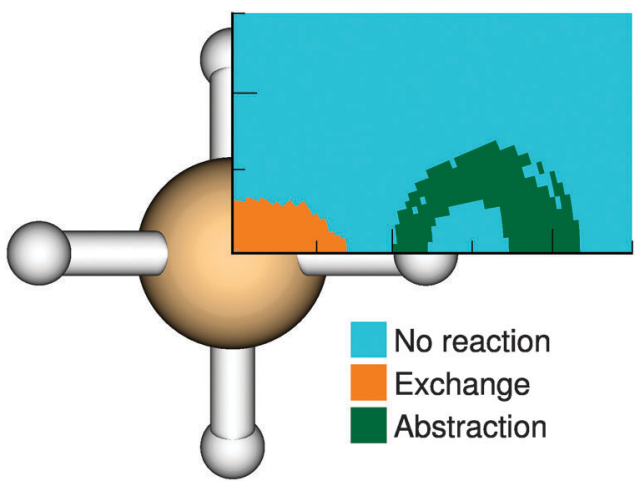

Fig. 9 A colour distribution depicts a map of the reactivity of trajectories (on PES2, with no initial vibrational energy) for a particular $\mathrm{SiH}_{4}-\mathrm{H}$ orientation. The incoming $\mathrm{H}$ atom velocity is perpendicular to the plane of the page with an initial relative energy of $60 \mathrm{~m} E_{\mathrm{h}}$. Regions in the plane are shaded according to the fate of trajectories with the $\mathrm{H}$ atom aimed at that point relative to the $\mathrm{SiH}_{4}$ position shown.

of the potential before sufficient energy could transfer into the $\mathrm{Si}-\mathrm{H}$ bond to allow it to be broken. For near collinear $\mathrm{Si}-\mathrm{H}-\mathrm{H}$ collisions, the onset of low impact parameter collisions rebounding without reaction lay between 20 and $40 \mathrm{~m} E_{\mathrm{h}}$; for the orientation shown in Fig. 9, incoming $\mathrm{H}$ atoms started bouncing off the $\mathrm{H}$ atoms in $\mathrm{SiH}_{4}$ at energies between 40 and $60 \mathrm{~m} E_{\mathrm{h}}$. The integral effect of the rejection cones growing faster than the acceptance cones readily explains the drop in reaction cross section at high collision energy.

"Rainbow"-like effects were also evident; in which the interplay between vibrational and rotational energy transfer for glancing $\mathrm{H}-\mathrm{H}$ interactions leads to oscillation between reactive and non-reactive behaviour with small changes in impact parameter.

\section{4 $\mathrm{H}+\mathrm{Si}_{2} \mathrm{H}_{6} \rightarrow \mathrm{H}_{2}+\mathrm{Si}_{2} \mathrm{H}_{5}$}

A PES describing the $\mathrm{H}+\mathrm{Si}_{2} \mathrm{H}_{6}$ reaction was also grown using no ZPE initially in the $\mathrm{Si}_{2} \mathrm{H}_{6}$ reactant. The initial set of data points comprised 51 geometries selected from an IRC calculation scanning both directions from the $\mathrm{H} \cdot \cdots \mathrm{H}-\mathrm{Si}_{2} \mathrm{H}_{5}$ saddle point. An unexpected feature of this system was soon discovered. A large number of reactive trajectories did not produce abstracted $\mathrm{H}_{2}$. Rather, the incoming $\mathrm{H}$ atom bound to one of the $\mathrm{Si}$ atoms, transferring sufficient energy into the molecule to break the $\mathrm{Si}-\mathrm{Si}$ bond:

$$
\mathrm{H}+\mathrm{Si}_{2} \mathrm{H}_{6} \rightarrow \mathrm{Si}_{2} \mathrm{H}_{7} \rightarrow \mathrm{SiH}_{4}+\mathrm{SiH}_{3}
$$

Although no attempt has been made to optimise a saddle point for this process, course-grained investigations of the reaction path have revealed that the barrier for this reaction lies in the vicinity of $12 \mathrm{~m} E_{\mathrm{h}}$ (approximately $30 \mathrm{~kJ} \mathrm{~mol}^{-1}$ ) above the asymptotic energy of the reactants. The mixed basis set used in this work yields a reaction energy of $-51 \mathrm{~m} E_{\mathrm{h}}$ $\left(-134 \mathrm{~kJ} \mathrm{~mol}^{-1}\right)$ for this channel, around $20 \mathrm{~m} E_{\mathrm{h}}$ larger than at the QCISD/aug-cc-pVDZ level.

The region of configuration space energetically accessible in the $\mathrm{SiH}_{4}+\mathrm{SiH}_{3}$ exit channel was substantially larger than in the $\mathrm{H}+\mathrm{Si}_{2} \mathrm{H}_{6}$ or $\mathrm{H}_{2}+\mathrm{Si}_{2} \mathrm{H}_{5}$ regions, largely due to the additional rotational degrees of freedom. One might therefore expect a larger number of data points may be required to adequately describe the PES in this region than for the entrance channel and abstraction reaction exit channel. This was borne out by the variance and $h$-weight data point selection criteria choosing geometries clearly in this $\mathrm{Si}_{2} \mathrm{H}_{7}$ complex formation and dissociation channel for $75 \%$ of the first 390 data points added by Grow, despite comparable reaction probabilities for the abstraction and $\mathrm{Si}-\mathrm{Si}$ dissociation channels. As this latter channel is irrelevant for the H-passivated silicon surface application, for which this PES is being developed, a modification was made so that sampled trajectory points with $\mathrm{Si}-\mathrm{Si}$ distances greater than $5 \mathrm{a}_{0}(2.6 \AA)$ were excluded from consideration in the data point geometry selection procedure.

Similar to the $\mathrm{H}+\mathrm{SiH}_{4}$ case above, the PES generation procedure was periodically paused to run batches of trajectories at collision energies of 20 and $40 \mathrm{~m} E_{\mathrm{h}}$ (52.5 and $\left.105 \mathrm{~kJ} \mathrm{~mol}^{-1}\right)$. For these trajectories a maximum impact parameter of $7 \mathrm{a}_{0}(3.7 \AA)$ was found to be suitable. The resulting reactive cross sections are shown in Fig. 10. Once more there was little dependence on the number of data points after the first several hundred.

As for the $\mathrm{H}+\mathrm{SiH}_{4}$ reaction, a test set of geometries were selected at random from a batch of trajectories run at a collision energy of $40 \mathrm{~m} E_{\mathrm{h}}$ with a PES defined by 900 data points. The ab initio energy was evaluated at 500 points which were selected from geometries excluding those lying in the $\mathrm{SiH}_{4}+\mathrm{SiH}_{3}$ channel, with 200 coming specifically from geometries in the $\mathrm{H}_{2}+\mathrm{Si}_{2} \mathrm{H}_{5}$ product valley. The mean absolute interpolation error is also shown along with the $\mathrm{SiH}_{5}$ results in Fig. 7. The mean errors decreased with an increasing number of data points in a similar way to the $\mathrm{SiH}_{5}$ PES, reducing to around $0.25 \mathrm{~m} E_{\mathrm{h}}$ or less when more than 1400 data points had been added. The total range of the calculated energies was almost $70 \mathrm{~m} E_{\mathrm{h}}$.

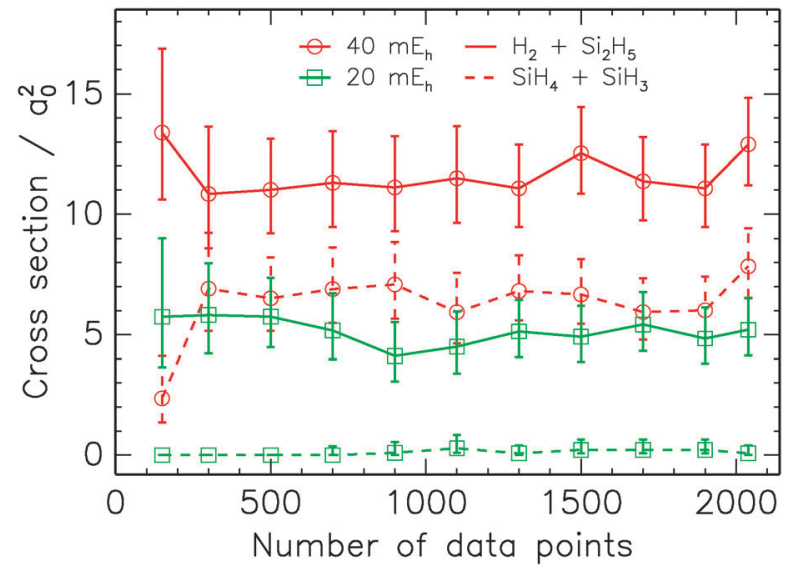

Fig. 10 Reaction cross sections for the two product channels of $\mathrm{H}+\mathrm{Si}_{2} \mathrm{H}_{6}$ are shown as a function of the number of data points. The lines are merely a visual aid, with solid lines indicating the $\mathrm{H}_{2}+\mathrm{Si}_{2} \mathrm{H}_{5}$ product, and the dashed lines indicating the $\mathrm{SiH}_{4}+$ $\mathrm{SiH}_{3}$ product. All trajectories have no initial vibrational energy in $\mathrm{Si}_{2} \mathrm{H}_{6}$. Results are shown for initial relative translational energies of $40 \mathrm{~m} E_{\mathrm{h}}\left(105 \mathrm{~kJ} \mathrm{~mol}^{-1}\right)$ and $20 \mathrm{~m} E_{\mathrm{h}}\left(52.5 \mathrm{~kJ} \mathrm{~mol}^{-1}\right) .95 \%$ confidence intervals are indicated. 


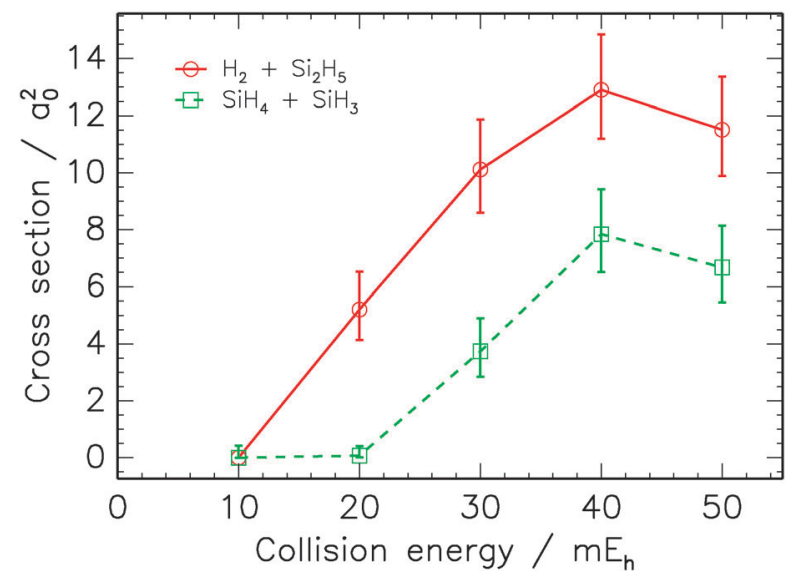

Fig. 11 Calculated reaction cross sections for $\mathrm{H}+\mathrm{Si}_{2} \mathrm{H}_{6}$ are shown as a function of the translational collision energy. 95\% confidence intervals are indicated, and the lines are merely visual aids.

Batches of 2100 trajectories were run on the PES defined by the final set of 2039 data points, at a number of collision energies. The resulting integral cross sections are shown in Fig. 11. The calculated cross section for the breaking the $\mathrm{Si}-\mathrm{Si}$ bond to form $\mathrm{SiH}_{4}+\mathrm{SiH}_{3}$ was around $5 \mathrm{a}_{0}{ }^{2}\left(1.5 \AA^{2}\right)$ smaller than that for hydrogen abstraction across the tested energy range. As for the $\mathrm{H}+\mathrm{SiH}_{4}$ reaction, at high collision energies the reaction cross sections tends to fall with increasing energy.

\section{PES for $\mathrm{H}+\mathrm{H}-\mathrm{Si}(111)$}

As discussed in section 2.2, the Level 1 fragmentation of Si(111) produces $4 \mathrm{SiH}_{4}$ and $12 \mathrm{Si}_{2} \mathrm{H}_{6}$ fragments per unit cell in the surface layer, and $8 \mathrm{SiH}_{4}$ and $16 \mathrm{Si}_{2} \mathrm{H}_{6}$ fragments per unit cell in the bulk of the crystal. Fig. 12 depicts the location of the surface fragments in relation to an incoming hydrogen atom. The addition of periodic copies of these surface fragments together with periodic copies of the bulk fragments reproduces the complete structure of the hydrogen terminated $\mathrm{Si}(111)$ surface. Note that all the hydrogen atoms in the crystal (which appear between, beside and below Si atoms in Fig. 12)

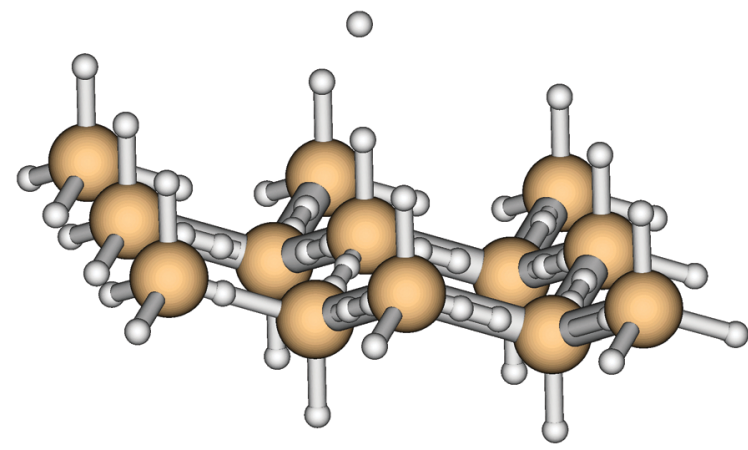

Fig. 12 This depicts the atoms which constitute the fragments of one surface cell of H-terminated $\mathrm{Si}(111)$, plus one incoming hydrogen atom. The hydrogen atoms that can be seen within and below the surface layer (rather than lying above the surface) are removed when the fragments for the entire cleaved crystal are summed with the appropriate coefficients, as in eqn (2.10). "cancel" in this summation to leave only those $\mathrm{H}$ atoms protruding above the surface.

The PES which describes the incoming $\mathrm{H}$ atom reacting with a surface $\mathrm{H}$ atom is given by the corresponding sum of PESs for $\mathrm{H}+\mathrm{SiH}_{4}$ and $\mathrm{H}+\mathrm{Si}_{2} \mathrm{H}_{6}$, as in eqn (2.11). To illustrate this PES, we have manufactured a crude approximation to a reaction path for this process as a path on which a $\mathrm{H}$ atom approaches the surface collinear with a $\mathrm{H}-\mathrm{Si}$ group, followed by breaking of the $\mathrm{H}-\mathrm{Si}$ bond and rebound of the $\mathrm{H}_{2}$ molecule. The corresponding reaction coordinate is simply the difference between the (initially bound) $\mathrm{H}-\mathrm{Si}$ bond length and the forming $\mathrm{H}-\mathrm{H}$ bond length. Fig. 13 presents the energy profile along this path for the PESs of $\mathrm{H}+\mathrm{SiH}_{4}$ (PES2) and $\mathrm{H}+\mathrm{Si}_{2} \mathrm{H}_{6}$, presented above. Fig. 13 also presents three profiles for $\mathrm{H}+\mathrm{H} \cdots \mathrm{Si}(111)$ for comparison with the profiles of the gas phase PESs. These three profiles were constructed using only the fragments for one surface cell (see Fig. 12) in eqn (2.11), using the fragments for a $3 \times 3$ segment of surface cells in eqn (2.11), and using one surface cell and the bulk cell immediately below this in eqn (2.11). We note that the energy profile for $\mathrm{H}+\mathrm{H} \cdots \mathrm{Si}(111)$ is dominated by the fragments shown in Fig. 12, and that the PES for $\mathrm{H}+\mathrm{H} \cdots \mathrm{Si}(111)$ is quantitatively different to the individual PES from which it is constructed.

The distance from the incoming $\mathrm{H}$ atom to atoms in the cleaved fragment, other than those in Fig. 12, is sufficiently large (at least along this path) that the interaction energy with these other atoms is near zero (that is, the energy is nearly equal to the asymptotic value for an infinitely distant $\mathrm{H}$ atom). The data that defines the gas phase PESs of section 4 are restricted to finite distances between the incoming $\mathrm{H}$ atom and the molecular reactant. For larger distances, the PES algorithm returns the asymptotic energy. Hence, in calculating the energy for $\mathrm{H}+\mathrm{H} \cdots \mathrm{Si}(111)$, only those $\mathrm{H}+\mathrm{SiH}_{4}$ and $\mathrm{H}+\mathrm{Si}_{2} \mathrm{H}_{6}$, interactions need be included for which the $\mathrm{H}$ atom is sufficiently close to the molecular reactant. This has important consequences for the computation time required to evaluate the $\mathrm{H}+\mathrm{H} \cdots \mathrm{Si}(111) \mathrm{PES}$.

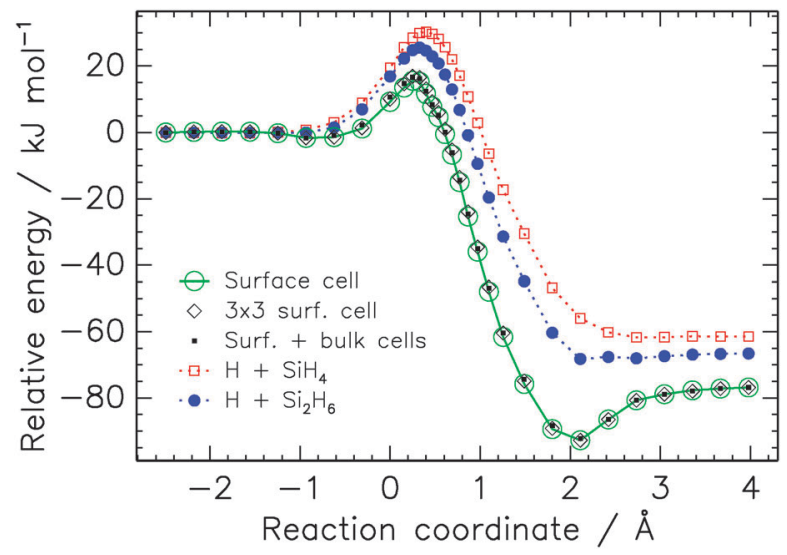

Fig. 13 The relative energy profile along a reaction path (see text) is shown for $(\square) \mathrm{H}+\mathrm{SiH}_{4},(\bullet) \mathrm{H}+\mathrm{Si}_{2} \mathrm{H}_{6},(\bigcirc) \mathrm{H}+$ one surface cell of $\mathrm{H}-\mathrm{Si}(111) ;(\diamond) \mathrm{H}+$ nine surface cells $(3 \times 3)$ of $\mathrm{H}-\mathrm{Si}(111)$; and $(\square)$ $\mathrm{H}+$ one surface cell and one bulk cell of $\mathrm{H}-\mathrm{Si}(111)$. 


\section{Concluding remarks}

We have described how the systematic fragmentation methods developed for molecules and crystals can be applied to represent a cleaved crystal in terms of bulk and surface fragments. At the lowest level of fragmentation, these fragments are monomers and dimers of functional groups; $\mathrm{SiH}_{4}$ and $\mathrm{Si}_{2} \mathrm{H}_{6}$ in the case of silicon. The electronic energy of a cleaved crystal can then be expressed as a sum of the energies of these relatively small molecules. This fragmentation approximation is not valid for metals or for conducting crystals (or aromatic molecules) where the electronic wavefunctions are essentially delocalised.

The PES for the reaction of a molecule with a cleaved (non-conducting) crystal surface can similarly be expressed as a sum of the PESs for that molecule reacting with the small molecular fragments. In our illustrative example, $\mathrm{H}$ atom reacting with hydrogen-terminated $\mathrm{Si}(111)$, the PES is given at Level 1 fragmentation as a sum of PESs describing reactions (3.2) and (3.3). We have shown that the energies of saddle points and products for hydrogen reacting with larger silanes and a cluster of silicon atoms on the (111) surface are accurately reproduced by a Level 1 fragmentation.

PESs for reactions (3.2) and (3.3) have been evaluated using the Grow methodology. The data sets and software required to evaluate these PES are included in the supplementary material. Using these small molecule PESs, the energy profile on a reaction path for a hydrogen atom reacting with the $\mathrm{H}-\mathrm{Si}(111)$ surface has been evaluated to illustrate some important characteristics of the complete PES.

It is important to note that further methodology development is necessary to complete the construction of molecule-surface PESs. As discussed in section 2.3, the construction of a Level 1 PES for a molecule-surface reaction is only the first step towards a chemically accurate PES. The Level 2 (and possibly Level 3, but probably not higher) PECSs must be constructed to ensure close convergence to the exact complete PES. The Grow methodology uses classical trajectories to explore the relevant configuration space in order to choose the most appropriate locations for evaluation of ab initio data. It is likely that the data point locations appropriate for the gas phase reactions of reactions (3.2) and (3.3) do not include all the appropriate locations for $\mathrm{H}+\mathrm{H} \cdots \mathrm{Si}(111)$. Hence, once the Level 1 PES has been constructed, further exploration of this molecule-surface PES with classical trajectories is probably necessary to include additional ab initio data in the small molecule PES data sets. It may also be possible to use quantum dynamics methods currently under development to select points where further refinement of the PESs should be made. $^{68}$

A major advantage of the fragmentation approach used herein is that high levels of $a b$ initio theory can be applied to the construction of these small molecule PESs and PECSs. There is no restriction to density functional methods or periodic-boundary-condition (PBC) electronic structure methods. Hence, we might hope to construct PESs for molecule-surface reactions that approach chemical accuracy.

\section{Acknowledgements}

This work was partly funded by a grant from the Australian Research Council. The authors acknowledge a grant of computer time from the ANU Supercomputer Facility.

\section{References}

1 L. M. Raff, M. Malshe, M. Hagan, D. I. Doughan, M. G. Rockley and R. Komanduri, J. Chem. Phys., 2005, 122, 084104.

2 S. Manzhosa, J. Chem. Phys., 2006, 125, 084109.

3 A. Brown, B. J. Braams, K. Christoffel, Z. Jin and J. M. Bowman, J. Chem. Phys., 2003, 119, 8790.

4 W. K. Park, J. Park, S. C. Park, B. J. Braams, C. Chen and J. M. Bowman, J. Chem. Phys., 2006, 125, 081101.

5 X. Huang, B. J. Braams, J. M. Bowman, R. E. A. Kelly, J. Tennyson, G. C. Groenenboom and A. v. d. Avoid, J. Chem. Phys., 2008, 128, 034312.

6 M. J. T. Jordan, K. C. Thompson and M. A. Collins, J. Chem. Phys., 1995, 102, 5647.

7 R. P. A. Bettens and M. A. Collins, J. Chem. Phys., 1999, 111, 816.

8 M. A. Collins, Theor. Chem. Acc., 2002, 108, 313.

9 C. R. Evenhuis and M. A. Collins, J. Phys. Chem. A, 2009, 113, 3979.

10 T. Hollebeek, T.-S. Ho, H. Rabitz and L. B. Harding, J. Chem. Phys., 2001, 114, 3945.

11 R. Dawes, D. L. Thompson, Y. Guo, A. F. Wagner and M. Minkoff, J. Chem. Phys., 2007, 126, 184108.

12 C. Díaz, E. Pijper, R. A. Olsen, H. F. Busnengo, D. J. Auerbach and G. J. Kroes, Science, 2009, 326, 832.

13 D. A. McCormack, R. A. Olsen and E. J. Baerends, J. Chem. Phys., 2005, 122, 194708.

14 I. M. N. Groot, J. C. Juanes-Marcos, C. Díaz, M. F. Somers, R. A. Olsen and G. J. Kroes, Phys. Chem. Chem. Phys., 2010, 12, 1331

15 P. N. Abufager, C. Crespos and H. F. Busnengo, Phys. Chem. Chem. Phys., 2007, 9, 2258.

16 J. Ludwig and D. G. Vlachos, J. Chem. Phys., 2007, 127, 154716.

17 C. Crespos, M. A. Collins, E. Pijper and G. J. Kroes, J. Chem. Phys., 2004, 120, 2392

18 H. M. Netzloff and M. A. Collins, J. Chem. Phys., 2007, 127, 134113.

19 V. R. Saunders, R. Dovesi and C. Roetti, CRYSTAL03 User's Manual, Totino, 2003.

20 C. Pisani, M. Busso, G. Capecchi, S. Casassa, R. Dovesi, L. Maschio, C. Zicovich-Wilson and M. Schutz, J. Chem. Phys., 2005, 122, 94113.

21 G. E. Scuseria, J. Chem. Phys. A, 1999, 103, 4782.

22 G. E. Scuseria and P. Y. Ayala, J. Chem. Phys., 1999, 111, 8330.

23 P. Y. Ayala, K. N. Kudin and G. E. Scuseria, J. Chem. Phys., 2001, 115, 9698.

24 H. Stoll, Phys. Rev. B: Condens. Matter, 1992, 46, 6700.

25 P. Fulde, Theor. Chem. Acc., 2005, 114, 255.

26 K. Doll, M. Dolg and H. Stoll, Phys. Rev. B: Condens. Matter, 1996, 54, 13529.

27 B. Paulus, P. Fulde and H. Stoll, Phys. Rev. B: Condens. Matter, 1995, 51, 10572.

28 H. Stoll, Chem. Phys. Lett., 1992, 191, 548.

29 H. Stoll, J. Chem. Phys., 1992, 97, 8449.

30 R. M. Olson and M. S. Gordon, J. Chem. Phys., 2006, 124, 081105.

31 D. D. Zorn, M. A. Albao, J. W. Evans and M. S. Gordon, J. Phys. Chem. C, 2009, 113, 7277.

32 J. R. Shoemaker, L. W. Burggraf and M. S. Gordon, J. Phys. Chem. A, 1999, 103, 3245.

33 M. Svensson, S. Humbel, R. D. J. Froese, Toshiaki Matsubara, S. Sieber and K. Morokuma, J. Phys. Chem., 1996, 100, 19357.

34 M. A. Collins and V. A. Deev, J. Chem. Phys., 2006, 125, 104104.

35 M. A. Addicoat and M. A. Collins, J. Chem. Phys., 2009, 131, 104103.

36 M. A. Collins, J. Chem. Phys., 2007, 127, 024104.

37 G. P. Lopinski, D. D. M. Wayner and R. A. Wolkow, Nature, 2000, 406, 48.

38 R. A. Wolkow, Annu. Rev. Phys. Chem., 1999, 50, 413. 
39 J. W. Lyding, G. C. Abeln, T.-C. Shen, C. Wang and J. R. Tucker, J. Vac. Sci. Technol., 1994, B 12, 3735.

40 J. Zikovskyand, S. A. Dogel, A. J. Dickie, J. L. Pitters and R. A. Wolkow, J. Vac. Sci. Technol., 2009, A 27, 248.

41 S. R. Schoeld, N. J. Curson, M. Y. Simmons, F. J. Rueß, T. Hallam, L. Oberbeck and R. G. Clark, Phys. Rev. Lett., 2003, 91, 136104.

42 G. A. Ferguson, S. Rivillon, Y. Chabal and K. Raghavachari, J. Phys. Chem. C, 2009, 113, 21713.

43 M. Dai, Y. Wang, J. Kwon, M. D. Halls and Y. J. Chabal, Nat. Mater., 2009, 8, 825.

44 D. W. Zhang and J. Z. H. Zhang, J. Chem. Phys., 2003, 119, 3599.

45 Y. Mei, C. Ji and J. Z. H. Zhang, J. Chem. Phys., 2006, 125, 094906.

46 X. H. Chen, D. W. Zhang and J. Z. H. Zhang, J. Chem. Phys., 2004, 120, 839 .

47 D. W. Zhang and J. Z. H. Zhang, J. Theor. Comput. Chem., 2004, $3,43$.

48 V. Deev and M. A. Collins, J. Chem. Phys., 2005, 122, 154102.

49 R. P. A. Bettens and A. M. Lee, J. Phys. Chem. A, 2006, 110, 8777.

50 V. Ganesh, R. K. Dongare, P. Balanarayan and S. R. Gadre, J. Chem. Phys., 2006, 125, 104109.

51 K. Babu, V. Ganesh, S. R. Gadre and N. E. Ghermani, Theor. Chem. Acc., 2004, 111, 255.

52 W. Li, T. Fang and S. Li, J. Chem. Phys., 2006, 124, 154102.

53 W. Li, S. Li and Y. Jiang, J. Phys. Chem. A, 2007, 111, 2193.

54 M. A. Collins and V. A. Deev, J. Chem. Phys., 2006, 125, 104104.

55 N. W. Ashcroft and N. D. Mermin, Solid State Physics, Holt, Rinehart And Winston, New York, 1976.

56 M. J. Frisch, G. W. Trucks, H. B. Schlegel, G. E. Scuseria, M. A. Robb, J. R. Cheeseman, G. Scalmani, V. Barone, B. Mennucci, G. A. Petersson, H. Nakatsuji, M. Caricato, X. Li, H. P. Hratchian, A. F. Izmaylov, J. Bloino, G. Zheng, J. L. Sonnenberg, M. Hada, M. Ehara, K. Toyota, R. Fukuda, J. Hasegawa, M. Ishida, T. Nakajima, Y. Honda, O. Kitao, H. Nakai, T. Vreven, J. J. A. Montgomery, J. E. Peralta,
F. Ogliaro, M. Bearpark, J. J. Heyd, E. Brothers, K. N. Kudin, V. N. Staroverov, R. Kobayashi, J. Normand, K. Raghavachari, A. Rendell, J. C. Burant, S. S. Iyengar, J. Tomasi, M. Cossi, N. Rega, J. M. Millam, M. Klene, J. E. Knox, J. B. Cross, V. Bakken, C. Adamo, J. Jaramillo, R. Gomperts, R. E. Stratmann, O. Yazyev, A. J. Austin, R. Cammi, C. Pomelli, J. W. Ochterski, R. L. Martin, K. Morokuma, V. G. Zakrzewski, G. A. Voth, P. Salvador, J. J. Dannenberg, S. Dapprich, A. D. Daniels, Ö. Farkas, J. B. Foresman, J. V. Ortiz, J. Cioslowski and D. J. Fox, Gaussian 09, Gaussian, Inc, Wallingford CT, 2009.

57 Y. Zhao, N. E. Schultz and D. G. Truhlar, J. Chem. Theory Comput., 2006, 2, 364.

58 J. Ischtwan and M. A. Collins, J. Chem. Phys., 1994, 100, 8080.

59 K. C. Thompson and M. A. Collins, J. Chem. Soc., Faraday Trans., 1997, 93, 871.

60 K. C. Thompson, M. J. T. Jordan and M. A. Collins, J. Chem. Phys., 1998, 108, 830.

61 W. L. Hase, R. J. Duchovic, X. Hu, A. Komornicki, K. F. Lim, D.-h. Lu, G. H. Peslherbe, K. N. Swamy, S. R. Van de Linde, A. Varandas, H. Wang and R. J. Wolf, QCPE Bull., 1996, 16, 671. 62 J. F. Castillo, F. J. Aoiz and L. Bañares, Chem. Phys. Lett., 2002, 356, 120.

63 J. F. Castillo, M. A. Collins, F. J. Aoiz and L. Bañares, J. Chem. Phys., 2003, 118, 7303.

64 H. P. Hratchian and H. B. Schlegel, J. Chem. Theory Comput., $2005,1,61$.

65 A. Agresti and B. A. Coull, Am. Statistian, 1998, 52, 119.

66 J. Cao, Z. Zhang, C. Zhang, K. Liu, M. Wang and W. Bian, Proc. Natl. Acad. Sci. U. S. A., 2009, 106, 13180.

67 W. Zhang, Y. Zhou, G. Wu, Y. Lu, H. Pan, B. Fu, Q. Shuai, L. Liu, S. Liu, L. Zhang, B. Jiang, D. Dai, S.-Y. Lee, Z. Xie, B. J. Braams, J. M. Bowman, M. A. Collins, D. H. Zhang and X. Yang, Proc. Natl. Acad. Sci. U. S. A., 2010, 107, 12782.

68 T. J. Frankcombe, M. A. Collins and G. A. Worth, Chem. Phys. Lett., 2010, 489, 242. 